\title{
Power Trade, Welfare, and Air Quality
}

\author{
Department of Economics and Finance \\ University of Guelph
}

Discussion Paper 2014-01 


\title{
Power Trade, Welfare, and Air Quality
}

\author{
Abdurrahman Aydemir and Talat S. Genc ${ }^{*}$
}

Abstract: We use detailed data from all generators in the Ontario wholesale electricity market to investigate cross-border electricity trade and its impact on air emissions and welfare in Ontario. Using the technical characteristics of the generators and financial data we run a competition model every hour and find that the model generates actual prices and outputs with $94.4 \%$ and $96 \%$ accuracy, respectively. We show that there is a significant welfare gain from power trade. The air emissions savings are also considerable. For instance, when hourly imports double from current levels $\mathrm{CO} 2$ emissions decrease around $13 \%$, and market prices reduce $5.4 \%$. In autarky, $\mathrm{CO} 2, \mathrm{SO} 2$, NOx emissions increase $12 \%, 22 \%, 16 \%$, resp., the prices go up $5.8 \%$, and the price volatility rises $12 \%$. However, the impact of negative wholesale prices on market outcomes is small.

Keywords: Electricity trade; interconnected markets; air emissions; welfare

JEL codes: F18, L13, L94

Aydemir: College of Arts and Social Sciences, Sabanci University, Istanbul, Turkey (email: aaydemir@su.edu.tr);

Genc: Department of Economics, University of Guelph, Guelph, N1G2W1, ON, Canada, (email:

tgenc@uoguelph.ca).

${ }^{*}$ Corresponding author. Phone: 1.519.824.4120 ex56106

We thank Mike Hoy, Rene Kirkegaard, Steve Kosempel, Esra D. Kaygusuz, and the seminar participants at the Independent Electricity System Operator (IESO), the Fields Institute, Guelph, SUNY-Buffalo, Sabanci, ITU Energy Institute, and INFORMS Conference 2012 for valuable comments. 


\section{Introduction}

While restructuring of the electricity industries has been evolving in many countries, crossborder electricity trade over interconnections has been growing, and it becomes an interesting issue to investigate. There is a significant electricity trade among the Canadian provinces, as well as, cross-border trade between Canadian provinces and the US states. For example, Canada, a net exporter of electricity to the US, exported $51,108 \mathrm{GWh}$ electricity and imported 17,490 $\mathrm{GWh}$ electricity from the US in 2009. ${ }^{1}$ International electricity trade among the European countries has also grown significantly over the years. Despite the growing importance of electricity trade across jurisdictions the implications of trade on market outcomes has not been studied. This paper examines how electricity trade, between Ontario and a pair of regions in Canada and the US, impacts market prices, electricity consumption levels, air quality and total surplus in Ontario.

A number of papers have examined various issues in the restructured electricity markets including Green and Newbery (1992), Wolfram (1999), Borenstein et al (2000), Borenstein et al. (2002), Joskow and Kahn (2002), Wolak (2007), Hortacsu and Puller (2008), Mansur (2008), Genc (2009), Genc and Reynolds (2011), Fowlie et al (2012). These papers cover market power analysis, optimal bidding behavior, transmission investments, forward contracting, the role of auction institutions on the market outcomes, impact of market structure on welfare, and environmental issues stemming from power generation. In this literature, electricity trade analysis and the impact of electricity trade on market outcomes have not been addressed. ${ }^{2}$

Electricity has unique features relative to other tradable goods that make power markets an interesting case to study. Electricity is non-storable (in large scale), it needs continuous matching of demand and supply, it moves at the speed of light, and the wholesale electricity price can be negative due to network constraints and imbalances between supply and demand. Moreover, unlike other tradable goods the electricity transfers are continuous and simultaneous called wheeling through transactions: in almost all trading hours a market can both import and export

\footnotetext{
${ }^{1}$ National Energy Board- http://www.neb.gc.ca/clfnsi/rnrgynfmtn/sttstc/lctrctyxprtmprt/lctrctyxprtmprt-eng.html

${ }^{2}$ In a trade context, Genc et al. (2012) empirically test the relationship between electricity prices and trade activities and find that imports are unambiguously related to prices (significant Granger causality). Ontario's electricity trade through the neighboring twelve interconnections indicates that three interties have a significant impact on price, two of which are the largest ones.
} 
energy between jurisdictions. The reasons for simultaneous exports and imports are related to the expectations on price differentials between the interconnected markets, and uncertainties in the demand (e.g., temperature related) and supply conditions (e.g., unscheduled generator failures). These characteristics of electricity markets constitute a novelty.

Electricity trade can impact generation behavior of power producers, and the mixture of power portfolios that firms hold and invest in and the way they produce. Trade can also cause substitution of fuel resources across markets as the most polluting technologies are usually the most expensive technologies (e.g., oil and gas). ${ }^{3}$ Thus, electricity trade not only has implications for prices, consumption and total surplus but also for emission levels. Although electricity trade across jurisdictions has been expanding the extent to which it affects prices and total surplus (welfare) has not been estimated. Similarly, the impact of electricity trade on emissions in a given market is unknown. To our knowledge this is the first paper contributing to the literature by investigating how electricity trade affects the market dynamics and the air quality in a given economy. Our paper is related to the papers by Borenstein, Bushnell and Stoft (2000) and Wolak (2012) who examine competitiveness benefits of transmission expansions and demonstrate that transmission congestion softens the competition and transmission expansion (or perception of uncongested transmission) enhances the amount of competition. Similar to their findings, we also show how increased import quantities facilitated by increased transmission lead to lower market prices.

The electricity generation is the most air polluting industry (in terms of greenhouse gas emissions, GHG) in many parts of the world and is associated with climate change, although it contributes to around 3\% of GDP. ${ }^{4}$ The key air pollutants relevant to the electricity industry are carbon dioxide (CO2), sulfur dioxide (SO2) and the nitrogen oxides (NOx). These pollutants, which affect public health and the environment, are kept tract by the environmental policy

\footnotetext{
${ }^{3}$ Coal is exception as it is relatively cheaper and highly dirtier technology. However, due to the environmental protocols, the Green Energy Acts and public pressure, there is an aversion to coal plants and many countries aim to either phase out all of their coal generators or partially substitute them with natural gas and/or green technologies. Ontario has shut down most of its coal-fired generation units as of 2013.

${ }^{4}$ Including transmission, distribution, capital investments and others (labor, equipment, environmental protection measures) it becomes a major contributor to national GDP. The Canadian electricity industry directly employs 105,000 people in production, transmission and distribution sectors (source: http://knowyourpower.ca/the-value-ofelectricity/the-value-of-electricity/).
} 
agencies. The impact of electricity trade on emissions has policy implications on meeting environmental targets and investing in transmission network. Several environmental protocols (like Kyoto, Copenhagen) and Renewable Energy Laws (also known as Green Energy Acts) have aimed to abate air pollution. We argue that electricity trade could serve to the same purpose and alleviate the emissions. A market that heavily depends on dirty production technologies could import cheap and clean energy from a neighboring jurisdiction using cleaner technology and reduce its emissions (like the New York market importing clean and cheap hydroelectric energy from the Quebec market). There are a few studies in the literature addressing the impact of merchandise trade on environmental pollution (Antweiler et al. (2001), Cole (2004), Grether and De Melo (2004), Frankel and Rose (2005), Levinson (2009), Peters et al. (2011)). This paper contributes to this growing literature by focusing on trade where exports and imports of the same product (electricity) is simultaneous and by quantifying their impact on air pollution in a given economy ${ }^{5}$. The paper also discusses the role of different production technologies causing the observed pollution levels.

In this paper we study electricity trade between the Ontario wholesale electricity market and other national and international jurisdictions incorporating New York, Michigan, Minnesota, Manitoba and Quebec wholesale electricity markets. The Ontario market has several unique features relative to the other electricity markets (in terms of volatility and trade volumes), and we have detailed firm and market level data that are suitable to study environmental and welfare issues related to electricity trade. The Ontario market has significant interconnections with large regulated (Manitoba and Quebec) and liberalized (New York, Michigan, Minnesota) markets by the transmission grid over which the electricity trade occurs. The Ontario market has very volatile prices (the most volatile relative to the other restructured markets in the neighborhood) and relies on trade activities to clear its real-time market in its 5-minute wholesale electricity

\footnotetext{
${ }^{5}$ Related to air pollutants, Amor et al. (2011) calculate CO2 emission savings from electricity trade between hydropower based Quebec and the adjacent markets using exports and imports data. They heuristically identify the marginal electricity production technology in each jurisdiction to be able to determine the marginal technology which is replaced by the exports/imports. They calculate that Quebec exports avoided $28.3 \mathrm{Mt}$ of CO2 emissions.
} 
auctions. ${ }^{6}$ The main goal of electricity traders (generation firms and merchant firms) is to benefit from price differentials within the interconnected markets. The available trade capacity, which essentially poses a trade barrier, between Ontario and its neighboring jurisdictions is often 4,000 MW which is almost one-sixth of the total available production capacity, and is capable of satisfying almost two-ninths of the average electricity demand in Ontario. ${ }^{7}$ The market value of wholesale electricity sales (revenue for producers) in Ontario is $\$ 7.9 \mathrm{~b}, \$ 8.3 \mathrm{~b}$ and $\$ 8.8 \mathrm{~b}$ through 2006-2008, resp. The value of the trade (value of imports and exports combined) is nearly $\$ 0.8 \mathrm{~b}$, $\$ 1 \mathrm{~b}$, and $\$ 1.7 \mathrm{~b}$, and the imports meet 3.8\%, 4.3\%, and $6.5 \%$ of the market demand in the same period. As we show in this paper, even if the trade quantities were small they could make a sizable contribution to the market outcomes and environment by avoiding price spikes and abating air pollution.

This paper does not construct a trade model where exports and imports between the trading jurisdictions are determined in equilibrium. This could be an interesting research topic, but it is beyond the scope of current paper. Indeed, such study may not be feasible at all in the current setting of the model which uses very detailed generator/firm/market level data. For instance, to examine impact of imports on emissions levels in all markets that are interconnected, one needs to have generator level data incorporating their technical characteristics, cost functions, and market level data including demand functions, and generators' actual outputs, among others, in every market. This sort of data is not available to us for the region interconnecting Ontario, Manitoba, Quebec, New York, Minnesota, and Michigan wholesale electricity markets. Even if someone could obtain such novel data encompassing this region, for example, Michigan, or New York, or Quebec is also separately linked and trading with their neighboring electricity markets other than the above mentioned markets. Therefore, a number of markets that are interconnected in the networks will increase, and hence, e.g., the net emission impact of New York's export to, say Ontario, will not be tractable at all. Due to these reasons we will focus on a single market (which is Ontario) and its trade within the network it is all connected. Our main contribution is

\footnotetext{
${ }^{6}$ The real time market is settled every 5 minutes; however buyers (e.g., distribution companies and large industrial consumers) pay the hourly price called Ontario Hourly Energy Price (HOEP), which is the average of 5 minute prices in an hour. The price volatility in Ontario is higher than the ones in neighboring jurisdictions such as New England, New York and Pennsylvania-New Jersey-Maryland Interconnection.

${ }^{7}$ While actual installed transmission capacity between Ontario and its neighboring jurisdictions amounts to 6,000 MW, often $4000 \mathrm{MW}$ is used for trade due to the network constraints.
} 
that this paper quantifies the impact of imports/exports on market prices, total market surplus, generation behavior, and air emissions levels, which all have policy implications in transmission investments and meeting national and international emissions targets.

Our first goal is to model competition and then examine how trade changes equilibrium market outcomes and emission levels in the Ontario market. We calibrate a capacity constrained repeated Cournot model using hourly changing market parameters such as available production capacities of generators, costs, and demand. We examine the effects of trade activities on GHG, mainly $\mathrm{CO} 2$, as well as on the other major air pollutants such as SO2 and NOx gases which are responsible for acid rain and smog. In particular, we quantify changes in market prices, firm outputs and emissions as the actual and counterfactual trade scenarios unfold. We also measure hourly and aggregate changes in total surplus (consumer and producer surplus) as these trade scenarios materialize. We study two counterfactual scenarios; the first one is referring to zero imports or exports and the second one is dealing with doubling their observed values. These scenarios aim to illustrate the effects of reduced or increased trade activity. Zero import or export scenario mimics the autarky market setting. Doubling imports or exports is an interesting and feasible scenario in the Ontario market setting, signifying higher trade volumes. Indeed, we observe significant changes in trading activities over time. For example, there has been a steady increase in maximum hourly export levels which have doubled over the 2002-2011 period ${ }^{8}$. This has been accompanied with significant investments in transmissions between Ontario and the neighboring jurisdictions allowing for large trade volumes.

Among the 563 generators in the Ontario market there are many small generators which are owned by independent firms and are treated as fringe players who are price-takers. There are a few large firms whose installed capacities are above $1000 \mathrm{MW}$, and we assume they are dominant firms and are able to exercise market power. Therefore, we employ dominant firms and competitive fringe suppliers Cournot competition model in which firms decide what portion of their available capacities to offer to the market for a given hour. All power generators including the fringe suppliers are constrained by their available production capacities which are different than the installed capacities and vary from hour to hour. ${ }^{9}$

\footnotetext{
${ }^{8}$ See Figure A9 in the appendix for changes in maximum hourly trading levels over 2002-2011 period.

${ }^{9}$ Available production capacities along with the actual outputs are published by the IESO at its website www.ieso.ca
} 
In examining the Ontario wholesale electricity market, first we use financial data and technical characteristics of generators, emission rates, permit prices, and hourly availabilities of generators and their capacities, and construct marginal production cost for each firm for each hour of the day in the study period, which spans the hours of 2007-2008. Our unique data set which covers actual hourly outputs and available capacities of all generators enables us comparing (our and the system operator's) model predictions to the actual realizations. Second, we calibrate every hour the wholesale electricity industry and take into account of changing market conditions (available generators, production capacities, demand, costs and prices) to predict market prices, outputs and emission levels of firms. Technically, one hour before market clears we update our model parameters and variables, and construct cost and demand functions, and then run our competition model to predict the hour-ahead market transaction price and production quantities of strategic and non-strategic firms. We propose a tractable repeated game, and show that our competition model has a high predictive power. For instance, in March 2008 we find that the hourly mean absolute error between our price estimations and the actual realizations is \$2.48. It is \$14.99 between the auctioneer's (The Independent Electricity System Operator, IESO) price estimations and the realizations. In terms of the mean absolute errors (MAE), the model price predictions are on average 3.5 times better than the IESO predictions in a year. Also our price predictions are close to the actual market prices and the model replicates the hourly equilibrium prices with $94.4 \%$ accuracy.

Given the high predictive power of the model, we then address some policy questions related to the environment and sustainability of the market. Specifically we measure; a) greenhouse gas emissions along with other gases offset in Ontario due to the trade between the Ontario market and its neighbors; and b) the impact of trade (imports and exports) on the market dynamics and the total surplus in Ontario. We find that when the imports double from the current levels, the $\mathrm{CO} 2$ emissions reduce around 13\%, and the market prices decrease $5.4 \%$ in Ontario. Furthermore, in autarky situation in which the Ontario market participants would not import from any neighboring markets, $\mathrm{CO} 2, \mathrm{SO} 2$, and $\mathrm{NOx}$ emissions would increase by $12 \%, 22 \%$, $16 \%$, resp. The Ontario market price would increase $5.8 \%$, and price volatility (standard deviation) would increase 12\%. The welfare gain (change in consumers and producers surplus) from electricity trade increases by $50 \%$ as a result of trade compared to autarky (that is, when there is no imports). The same efficiency gain also applies when imports double from its current 
existing levels. This welfare gain incorporates the social cost of NOx and $\mathrm{SO} 2$ air pollution as firms internalize the permit prices of these pollutants in their cost calculations. We also compute the welfare loss when market prices are negative (negative prices are now frequently happening and posing a concern for market observers and participants) and find that the loss is very small.

We also calculate the dead-weight loss (DWL) in the existing market structure with respect to the efficient allocation for each hour from April 2007 to March 2008 in the Ontario wholesale market. We sum up the hourly DWL to find the total welfare loss (change in consumer plus producer surpluses) in the market in a year. We find that the total deadweight loss in the year is almost $\$ 342$ million, and this represents only 4.2 percent of the total wholesale energy cost $(\$ 8.2$ billion for the year) in the wholesale market, and suggests that the imperfect competitive nature of the Ontario market could be tolerable.

The organization of the paper is as follows. Sections 2 and 3 describe data, market structure, competition model and calibration framework. Section 4 presents an assessment of the model predictions, compares our predictions to the IESO predictions, and contrasts the actual outcomes to the firm level predictions. Section 5 deals with welfare analysis in the Ontario market with the presence of trade and the negative prices. Section 6 quantifies the emission savings with respect to several import scenarios. Section 7 extends the model and presents the role of exports on market prices and emissions. Finally, conclusions with policy implications are presented in the eighth section.

\section{Data and the Market Structure}

\section{Data}

We employ a detailed plant and market level data provided by the Independent Electricity System Operator (IESO). To the best of our knowledge these data sets have not used before, and include hourly export/import quantities, hourly production and available capacity of each generator, hourly market clearing prices and demand quantity, as well as technical features of generators and financial data. In the data we observe aggregate level of Ontario's exports, but do not know who is exporting what quantity. Similarly, we observe the aggregate import quantities from each neighboring market; however we do not have the data regarding which generators/firms are exporting into Ontario. Note that all exports are part of the aggregate market 
demand (equals Ontario demand plus export demand) and imports are part of the aggregate supply, and hence they are priced in the Ontario market. We use one year hourly data accounting for 8784 observations for each variable starting from April 1, 2007, the time that the IESO started to publish its market price and demand quantity predictions, and ending with March 31, 2008. In the Ontario market there are 563 registered generators of which we have their efficiency rates (energy content and heat rate), emission rates (of $\mathrm{NOx}, \mathrm{SO} 2$, and $\mathrm{CO} 2$ ) and available hourly production capacities. ${ }^{10}$ The financial data obtained from Statistics Canada includes information on the amount of money spent for each fuel type (coal, nuclear, gas, oil, biomass, etc.) by the firms in a year. In addition, we have obtained one-hour, two-hour and three-hour ahead predispatch prices and quantities which are the estimates of market price and quantity demanded by the IESO before the market clears. We take into account of externality pricing, and use permit prices of the major air pollutants in constructing the marginal production cost of the generators. The details about the data sets are available in Appendix A.

\section{Market Structure}

In Ontario there is no day-ahead forward market and the share of bilateral contracts is tiny (almost zero due to the market design which mandates real-time power exchange) and the power transactions (purchase, sale, export/import) are carried out in the "pool" type real-time wholesale market. The auctioneer, so called the Independent Electricity System Operator (IESO), in the Ontario wholesale electricity market employs a dispatch scheduling and optimization algorithm to determine pre-dispatch sequence of prices and demand quantities for the future periods. The pre-dispatch prices are the predicted prices given the demand and supply forecast of the market. The algorithm is run every hour, and the pre-dispatch prices and quantities calculated each hour for the future hours are published at the IESO website, so that market participants could use the pre-dispatch data to reform their operations, planning and participation in the real-time market.

\section{Firms}

In a given hour we map all available generators to the owners of the firms before we construct their marginal production cost functions. In the modeling framework we will assume that

\footnotetext{
${ }^{10}$ The reference for the generators is the Environment Canada: Canadian Module Unit List-The Canadian Module Unit List is a fundamental modeling input to the Canadian IPM Base Case 2004. It is an inventory of all currently operating (or existing) electric generating units (EGUs) and planned-committed units and their relevant characteristics. The web-link for the reference is http://www.ec.gc.ca/air/default.asp?lang=En\&n=D6C16D01-1.
} 
dominant firms and competitive fringe competition model describes the economic behavior in the Ontario market. Indeed in Section 4 we will show that this competition model predicts the market outcomes with high accuracy. The dominant firms (each with more than $1000 \mathrm{MW}$ installed capacities) are Ontario Power Generation Inc (OPG), Bruce Nuclear Inc (Bruce), and Brookfield Renewable Energy Inc (Brookfield), and we assume the rest of the firms and generators as fringe suppliers (whose capacities are mostly less than $100 \mathrm{MW}$ ). In the premodeling stage, we performed a sensitivity test by increasing the number of strategic firms, by assuming one of the large fringe suppliers might be behaving strategically. Specifically, the candidate dominant firm could be TransAlta, a large producer based in Alberta that also produces in Ontario with its installed production capacity less than $1000 \mathrm{MW}$. When TransAlta was introduced as a strategic player, the model outcomes were not altered considerably. That is, the prices and outputs were almost identical whether we assume TransAlta a strategic player or a fringe supplier. This result could be expected due to the tradeoff between increased number of strategic firms and decreased number of fringe suppliers: in any case residual demand reduces whether we have one more strategic player or one less fringe supplier. Given that the model outcomes are not affected and its installed capacity is small relative to the production capacities of the dominant firms, we believe the Ontario market can be best characterized as having three dominant firms, with TransAlta being treated as a fringe firm.

\section{Cost Functions}

We construct marginal fuel cost of all generators which will be a function of fuel type and amount of fuel each generator burns, each generator's heat rate, energy content of each fuel type, and dollar amount spent for each fuel type. In addition, we calculate marginal emission cost of a generator which is a function of heat and emission rates and the permit prices of $\mathrm{SO} 2$ and NOx gases. We then add marginal emission cost to the marginal fuel cost to compute total marginal cost of production for each generator. In Appendix A we present the formula we use in calculating the total marginal costs.

In calculating hourly marginal production cost for each generator, our marginal cost formulation includes such information as efficiency rates (heat and emissions rates), actual total dollar amount spent on fuel, emission permit prices, and energy content of fuel. With this formulation we actually obtain a fixed average variable cost for a given generator, which represents the 
marginal cost value. An alternative formulation would incorporate using fuel prices directly as a way of approximating marginal production cost of the generation unit. One clear benefit of the second approach, at the expense of losing some critical price data such as actual expenditures used in the first approach, is that it would enable us to use varying marginal costs over the course of periods such as days, as the fuel spot prices could change over days.

Although we employ the former cost formulation, we will briefly discuss about the possible results if the latter approach were to be utilized. As a robustness check, we compare the most active (operating every hour in the study period) natural gas fired generator's marginal costs based on the Henry Hub natural gas spot prices and on our marginal cost formulation. We convert daily Henry Hub spot prices to hourly prices assuming the same prices over the hours of the day and then compare them to our hourly marginal costs. We find that during the study period the average hourly marginal cost based on the Henry Hub natural gas prices are just 14\% higher than the average hourly marginal cost based on our formulation. This marginal cost differential is meaningful as we would expect higher cost in case of the generator purchasing its natural gas from daily spot market rather than buying it (several months) earlier, as they do, at the wholesale contract price. Also, from the actual generation data the production from natural gas fired generators on average covers $7 \%$ of total market demand, and meets $8.6 \%$ of the demand during high demand periods (top quartile). Therefore, given that there is a small cost differential between our marginal costs and Henry Hub spot market fuel prices, and the output from all of natural gas fired generators meets a small portion of the total market demand and generation $^{11}$, and competition structure and the number of firms in the market also play a key role in price formation process, we conclude that using fuel spot prices as the opportunity cost of burning fuel, even when firms have fuel contracts, as opposed to our marginal cost formulation would not change the performance of the model and the results in the paper.

The marginal cost function at any hour $t$ is a nonlinear function in general. For OPG and the fringe firms we first construct the marginal cost functions every hour, which are step functions with multiple steps and jumps, and then approximate them with continuous functions (using the best fit criteria), as they have many generators. For instance, OPG has over 60 plants/generators. If we would directly use step cost functions of the fringe firms we would obtain a kinked residual

\footnotetext{
${ }^{11}$ Over $60 \%$ of the production comes from low cost hydro and nuclear stations.
} 
demand curve which would make the best response curves of strategic firms discontinuous and harder to solve for the optimum. Due to the large number of generators run by OPG, its marginal cost curve will resemble a continuous curve, and it is also convenient to differentiate the continuous functions. On the other hand, the marginal cost functions of other dominant firmsBruce and Brookfield- will be treated step cost functions because they have at most two steps. Therefore, there is no need for continuous function approximations of the cost curves of Bruce and Brookfield.

To construct the system marginal cost function which is representing the perfectly competitive supply, we horizontally add the capacities of all generators for a given price level. The impact of emission costs on the total marginal costs is small as the permit prices were small during our study period. In 2007, over the 33,266 MW installed production capacity, taking into account of all 563 generators, the average total marginal cost of production is $\$ 39.58$ and the average marginal fuel cost is $\$ 38.18$, assuming that marginal cost of hydropower production is nil. Hence, on average externality costs (permit prices) are raising the marginal cost of production only $\$ 1.40$ per MWh over all generators and average total marginal cost is 3.67\% higher than the average marginal cost incorporating only fuel costs. However, average marginal cost will drop, so will the average externality cost, when we take into account of the "used" generators (that were dispatched) in a given hour.

In our hourly calibrations for market predictions the system marginal cost figure will change every hour as the availability of generators and the available generation capacity will vary for each hour. Essentially, marginal cost curves will shift to right or left mainly due to the hourly changing available generation capacities.

In Figure 1, we plot the hourly Ontario electricity prices (HOEP), which are the market clearing prices charged to the wholesale buyers and distribution companies. We derive and then plot the hourly system marginal costs (the marginal cost of generator clearing the perfectly competitive market) over the year 2007 in the same figure. 


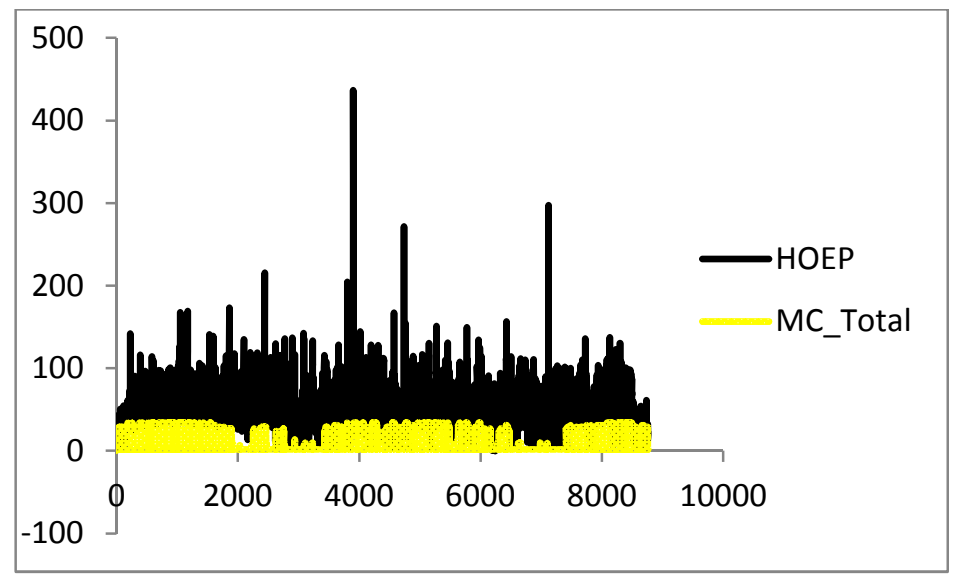

Figure 1: Time series plot of hourly market prices (HOEP=hourly Ontario energy price) and the system marginal costs in year 2007. X-axis represents hours, y axis denotes $\$ / M W h$.

In a perfectly competitive market we would expect prices to match system marginal costs in Figure 1. However, the realized prices, HOEP, are well above the marginal costs most of the time. Over all hours of year 2007, the average HOEP (equals $\$ 47.80 / \mathrm{MWh}$ ) is $517 \%$ above the average marginal cost price (equals $\$ 9.25 / \mathrm{MWh}$ ) of the used generators, implying a rigorous exercise of market power. Also in the figure we observe negative market clearing prices, which are well below the competitive prices (see Section 5.2 for the values of negative prices).

OPG has hydro, nuclear, coal, and natural gas fueled generators. Given the type of technology, available capacities, and the marginal costs for each generator, we obtain the marginal cost function for OPG. The total available capacity of OPG generators changes every hour; the minimum available total capacity is $12,900 \mathrm{MW}$, the maximum is $19900 \mathrm{MW}$, and the average is almost 16,900 MW per hour in year 2007.

Bruce nuclear has six nuclear generators/stations with the identical heat rates; hence its marginal cost function is constant in a year. Total production capacity from these six nuclear stations changes every hour, and in year 2007 its average total capacity is around 4,200 MW.

Brookfield has hydro, wind and natural gas-fired generators. As the rainfall, snowfall and wind are free of charge we assume zero marginal costs for the hydroelectric and wind power generators. Brookfield has a two-step marginal cost function. Its marginal cost is zero up to the total hydro and wind capacities. Since it has one natural gas-fired generator, its marginal cost is constant in a year. As its total marginal cost function has two steps, we do not smooth the step 
function. Marginal cost is zero up to a time varying renewable capacity, and then a positive marginal cost due to the natural gas unit. Its total available capacity varies from hour to hour, and its total production capacity is on average 1,000MW in year 2007.

There are many fringe producers who operate hydro, wind, biomass, and natural gas production technologies. They have different gas-fired generators with different heat rates, emission rates and capacities. The available capacities of gas turbines vary in between 0 and $580 \mathrm{MW}$ across generators. In 2007, the hourly average total available capacity of gas generators is near 2,170 $\mathrm{MW}$, it is around $500 \mathrm{MW}$ for biomass-fired generators, and $400 \mathrm{MW}$ for hydro and wind based generators. In sum, the hourly total average capacity of fringe suppliers amounts to approximately 2,800 MW in year 2007.

\section{The Model}

In modeling the behavior of electricity producers there are two commonly used approaches: a Cournot model where firm strategies involve production decisions, and a Supply function equilibrium (SFE) model in which firms choose price-quantity pairs as decision variables. Cournot assumption is fairly standard in analyzing market outcomes in electricity markets ${ }^{12}$, and SFE approach is generally used to analyze bidding behavior in electricity auctions ${ }^{13}$. In this paper we assume a quantity competition model as the latter one is very difficult to apply to the Ontario market setting in which firms are multiple, asymmetric, subject to capacity constraints and have non-convex costs. Thus far SFE models have not been applied to market power analyses in such a complex market setting due to the difficulty associated with solving differential equations in the presence of these constraints. Also, even in a simple market setting they predict multiple equilibria, posing an equilibrium selection problem. Furthermore, contrary to our repeated game setting in which model variables are changing every hour, SFE models are generally used in one-shot game settings in which market parameters are constant.

\footnotetext{
${ }^{12}$ See, for example, Borenstein and Bushnell (1999) or Borenstein et al. (2002).

${ }^{13}$ See Hortacsu and Puller (2008), and Genc and Reynolds (2011).
} 
We assume that the wholesale electricity demand is price responsive, downward sloping and linear in price. The hourly energy price ${ }^{14}$ or inverse demand is then formulated as follows:

$$
p(t)=a_{t}-b_{t} Q_{t}, \quad t=1,2, \ldots, T
$$

where $Q$ is the total market demand quantity. ${ }^{15}$ The intercept $a$ and slope $b$ vary every hour $t$ because of, for instance, change in temperature or industrial demand for electricity. The total market demand by definition equals Ontario market demand plus the exports to other jurisdictions. ${ }^{16}$ As the exports are part of the market demand they are implicitly incorporated into the quantity $Q$. However, in Section 7, we will treat exports explicitly and allow them vary with respect to certain scenarios.

Ontario's electricity consumption is significant as it is the manufacturing hub of Canada and there are large manufacturing customers who are subject to the real-time wholesale prices. In market demand calibrations we assume a constant point-price elasticity of demand $\varepsilon$, although it is possible to incorporate a variable elasticity term - across peak, shoulder and off-peak times into the model. ${ }^{17}$ There is no unanimous value for the price elasticity, and it can change from market to market. Price elasticity of demand is generally higher for the large volume industrial customers, who are subject to market prices, than the households, who are subject to fixed regulated (time-of-use) prices. In Ontario residential customers do not observe the real-time prices, and hence they cannot react to them. However, they can respond to the time-of-use prices. Empirical estimations of price elasticity of demand are in a large interval, ranging from 0 to 1

\footnotetext{
${ }^{14}$ The hourly market price (HOEP) is the price that is charged to the local distributing companies and other nondispatchable loads. It is also paid to self-scheduling generators.

${ }^{15}$ We might consider an alternative demand function such as logarithmic demand function with constant elasticity. The benefits of using linear demand in (1) is that i) equilibrium computations are easier with linear demand specification; ii) we are able to linearly add and subtract export and import levels to the demand curve and directly measure their impacts. Indeed, linear demand is commonly assumed in the literature. Furthermore, as we show in the model's performance section that the linear demand assumption along with the implemented competition structure yields a very good fit to the observed market outcomes.

${ }^{16}$ Alternatively, according to the IESO, market demand equals the total energy supplied from the IESOAdministered Market and the IESO calculates market demand by summing all outputs from generators registered in the market plus all scheduled imports to the province.

${ }^{17}$ However, the peak, shoulder and off-peak times vary from season to season, and the number of assumed elasticities would multiply. Therefore, for the sake of simplicity, we assume the same constant elasticity over hours of the day, and the days of the week.
} 
(see Lijesen 2007). The estimation differences come from the estimation method, frequency of the data, and the country studied.

We first search for a suitable $\varepsilon$ in the neighborhood of $[0.2,0.8]$ which is an acceptable range used in the literature. ${ }^{18}$ In our simulations we tried several candidate elasticities in that range and found that our competition model with $\varepsilon=0.6$ leads to better fit to the data. ${ }^{19}$ Using this elasticity figure along with the observed market price and demand quantity at time $t$, we calibrate the demand function parameters $a_{t}$ and $b_{t}$ in a simple approach. ${ }^{20}$ For a given fixed price elasticity of demand $\varepsilon$, which is equal to $\frac{d Q}{d p} \overline{\overline{Q_{t}}}$, where $\overline{p_{t}}$ and $\overline{Q_{t}}$ are the observed clearing price and output at time $t$, demand slope is $b_{t}=\frac{1}{\varepsilon} \frac{\overline{p_{t}}}{\overline{Q_{t}}}$. This can be used to determine demand intercept as $a_{t}=$ $\overline{p_{t}}+b_{t} \overline{Q_{t}}$. Hence demand curve changes at each time $t$ by the changing slope and intercept terms. Essentially, we pinpoint an affine demand curve passing through the observed market price and demand quantity every hour.

The fringe suppliers are comprised of many small independent producers who are price takers in the market. The import schedules are announced one hour before the dispatch and they are assumed to be known by all market participants. Then the residual demand faced by a dominant player is,

(2) $Q_{t}^{r}(p)=Q_{t}(p)-S_{t}(p)-I_{t}$

where $I$ is the total quantity scheduled to be imported and treated exogenous as they are known before market clears, $S(p)$ is the supply schedule of the fringe firms, and $Q(p)$ is the total market demand, which equals $a / b-p / b$, at hour $t$.

Given the residual demand and outputs of the other dominant players, each dominant firm maximizes its profit subject to the production constraint bounded by its production capacity and

${ }^{18}$ For example, Elkhafif (1992) estimate price elasticity of electricity demand in the range of 0.4 and 0.6. Borenstein and Bushnell (1999) run their simulations for elasticities 0.1, 0.4, and 1.0.

${ }^{19}$ Although the demand is inelastic, there are price responsive buyers called "dispatchable load" in the Ontario market. According to the IESO 2010 market's program (www.ieso.ca), there are 13 entities which operate as "dispatchable load" in the market and offer $700 \mathrm{MW}$ of potential demand response.

${ }^{20}$ For a given elasticity $\varepsilon$ there are infinitely many demand curves passing through a realized price-quantity pair. We choose an affine demand curve and find its coefficients. 
the non-negativity constraint for each power generator owned by this firm. Specifically, at hour $t$ a dominant firm $i$ maximizes its profit function ${ }^{21}$

$$
\pi_{i t}(.)=p_{t}\left(Q_{t}\right) q_{i t}-c_{i t}\left(q_{i t}\right)
$$

to choose its output level $q_{i t}$, which is subject to its available production capacity ${ }^{22} K_{i t} \geq q_{i t} \geq$ 0 . For the renewables such as wind and solar generators nameplate capacities are irrelevant due to the intermittence issues, instead we use their actual outputs as their "available capacities". At any time $t$ for a given price level $p$ total demand equals total supply:

$$
Q_{t}(p)=q_{i t}(p)+q_{-i t}(p)+S_{t}(p)+I_{t}
$$

where $q_{-i t}$ is the total output of the rival dominant firms.

The first order necessary conditions yield

$$
p_{t}^{\prime}\left(Q_{t}\right) q_{i t}+p_{t}\left(Q_{t}\right)-c_{i t}^{\prime}\left(q_{i t}\right)+\lambda_{i t}\left(K_{i t}-q_{i t}\right)+\mu_{i t} q_{i t}=0
$$

where $\lambda_{i t}$ and $\mu_{i t}$ are the non-negative multipliers, which will be relevant for output choice as some of the generators' production capacities are binding in equilibrium both in the model and the actual market.

In solving (5) for each firm $i$ at each period $t$ we do the following. For the dominant firm OPG who has several different technologies we smooth its marginal cost function $c_{O P G, t}^{\prime}\left(q_{i t}\right)$, which will be quadratic as derived in Appendix A. In model's performance assessment section, using its generators' announced available production capacities we distribute OPG's optimal aggregate output $q_{O P G, t}$ over all of its active generators at time $t$ in a merit order, from low cost to high cost manner. For the dominant firm Bruce, whose nuclear generators are identical, $c_{B r u c e, t}^{\prime}\left(q_{i t}\right)$ will

\footnotetext{
${ }^{21}$ For dominant firms with a few generators the cost function $c_{i t}(q(p))$ is separable in generator types, and the production capacity $K_{i t}$ is a vector of capacities of all generators owned by firm $i$. For dominant firms with many generators (e.g., the firm OPG generates power from over 60 generators), we aggregate the cost function and the production capacity over all generators.

${ }^{22}$ The available production capacity is exogenous and different than the installed capacity. The IESO defines the available capacity/capability as "(it) is a measure of the maximum amount of power that was capable of being produced by that unit during a given time." The available capacity can vary from hour to hour because of generation outages/deratings, regulatory/environmental restrictions, wind forecast, and the IESO's manual actions (e.g. to constrain a generator to fixed production level).
} 
be a one step function that changes every hour as its available capacities vary hourly. Its optimal output level $q_{\text {Bruce,t }}$ obtained solving (5) will be distributed over its generators according to their available capacities. The other dominant firm is Brookfield whose generators are two types: renewables (hydro and wind) and fossil-fuel based. Its marginal cost function $c_{B r o o k, t}^{\prime}\left(q_{i t}\right)$ has two steps; each step is for a fuel type. In (5) Brookfield's output $q_{\text {Bookfield,t }}$ is a two by one vector and we solve for the aggregate output from each fuel type. Specifically, for its intermittent wind generators we assign their actual wind outputs to its wind productions in the model. The rest of the renewable output is distributed to the hydro generators using their available production capacities. Its aggregate output from its identical gas-fired generators is distributed with respect to their available capacities. The rest of the firms in the market are fringe firms, who take market price $p$ given, and produce in aggregate $S_{t}(p)$, which is bounded by the aggregate available capacity $K_{S t}$. Its supply curve $S_{t}(p)$ is also smoothed as explained above and the production is distributed over generators in merit order and their outputs are constrained by their available capacities. Note that fringe capacities are important as we find in our calibrations that fringe supply is at the capacity for some time periods during which dominant firms unilaterally exercise significant market power.

Using the Ontario electricity industry data we run this competition model every hour to make predictions for the next hour similar to what the IESO does. After the predictions (price, output, emission) we update the cost functions and the model parameters such as demand coefficients, available production capacities, and scheduled import levels, then we rerun the model for the next hour predictions. This procedure is new in this paper, as the literature either takes the cost and/or demand functions fixed or discards variation in finer time scale (see, for example, Borenstein et al. (2002), and Genc and Reynolds (2011)).

Specifically, the timing of the model is that at hour $t-1$ all firms, strategic and fringe, update their available capacities, and construct and/or approximate the cost functions and figure out market demand curve for time $t$. It is assumed that scheduled imports at time $t$ is known at time $t-1$, because the imports are scheduled one hour before the actual dispatch. Similarly, available production capacities at hour $t$ are also assumed to be known by all producers at hour $t$ - 1 , as the system operator can share this information with the market participants. To calibrate the demand curve, we use price and load information at time $t$ to be able to derive the demand passing from 
the realization at time $t$. We then run the competition model $^{23}$ to predict the market price and the generation outputs for each firm (and then for each generator). At time $t$, for the period $t+1$, we repeat the same procedure until the end of the study period. In total we run the model for $T=8784$ hours in the year.

Ontario's electricity exports and imports with New York, Minnesota, Michigan, Manitoba and Quebec wholesale electricity markets are continuous and simultaneous. ${ }^{24}$ In this paper, we mainly focus on the imports. In the Ontario market exports are part of the total market demand and we explicitly model total market demand $Q_{t}(p)$. However, for the sake of completeness we take exports explicitly into account in Section 7, where we investigate their role on the air quality and welfare in Ontario.

\section{Assessing the Model Performance}

A firm's marginal cost function can change for each hour due to technical characteristics of generators, fuel costs, and the availability of the generators and variable production capacities. Given the hourly production cost estimations, we can determine for each hour whether the Ontario producers have any market power or not; if they have market power whether they exercise the market power. A simple price-cost mark-up test shows, it is also clear from Figure 1, that the Ontario market players do exercise market power and the prices are above the system marginal costs. Our model will also predict the same outcome, as the Cournot dominant firms facing small fringe firms will restrict the output and push the prices up well above the system marginal costs.

Our first goal is to test whether the competition model has any predictive power. We will compare the realized market prices and outputs to the predictions in Subsections 4.1 and 4.2. In Subsection 4.3 we will compare the firm level realized production quantities to the model estimations, which will make a difference in emissions evaluations.

\footnotetext{
${ }^{23}$ In calibrating the model, we write a code in AMPL language and employ National Argonne Lab NEOS server PATH solver, which is known to be state-of-the-art robust solver for the complementarity problems.

${ }^{24}$ The imports and exports of wholesale electricity in the Ontario market are carried out by traders and merchants like Cargill, Merrill Lynch, Powerex, Epcor, Allete, and Coral Energy, as well as incumbent power producers such as OPG, and Brookfield (source: National Energy Board monthly statistics).
} 


\subsection{Price Estimations}

To be able to address the policy issues, one has to make sure that the model predictions are close to the market realizations. The IESO predicts the market prices to give directions to the market participants. Similarly, we run our model every hour and compare the hourly model prices to the IESO predictions.

Table 1: Mean absolute error (MAE); IESO predictions versus the model predictions

\begin{tabular}{|l|c|c|}
\hline Time & $\begin{array}{l}\text { MAE (between IESO prices } \\
\text { and transaction prices) }\end{array}$ & $\begin{array}{l}\text { MAE (between model prices } \\
\text { and transaction prices) }\end{array}$ \\
\hline March 2008 hours & 15 & 2.49 \\
\hline August 2007 hours & 10.22 & 4.07 \\
\hline 4.2007-3.2008 all hours & 11.6 & 3.29 \\
\hline
\end{tabular}

In Table 1 we report the highest, lowest and average gaps between the model and IESO predictions in terms of mean absolute errors (MAE) in the year. This implies that the model and IESO price predictions were closest to each other in August and farthermost in March. In Figure 2, we draw the MAE over months for our model and the IESO price predictions. For all hours in the year, the MAE between our estimations and actual prices is $\$ 3.29$ per MWh, and the MAE between the operator's estimation and the actual prices is $\$ 11.6$ per MWh, which suggests that the MAE between our predictions and actual realizations is 3.5 times lower. The highest gap between the MAEs is observed in predicting hourly prices in March 2008. Our predicted MAE is $\$ 2.49$, and the operator's predicted MAE is $\$ 15$ in this month. The lowest gap is observed in a summer month of August in which our predicted MAE is $\$ 4.07$ and it is $\$ 10.22$ for the operator. Also, our best price predictions (the lowest MAE) occur in May 2007, where the MAE is $\$ 2.36$, and our worst predictions occur in a winter month February 2008 with MAE equals $\$ 4.51$. The system operator's worst price predictions also occur in February with MAE equals $\$ 15.06$, and their best predictions happen in September with MAE equals to $\$ 9.11$. The complete figure of MAE values are reported in Appendix B.

Also observe that the MAE calculated based on our model is a small number; that is our price predictions are very close to the market transaction prices, suggesting high predictive power of the model. 


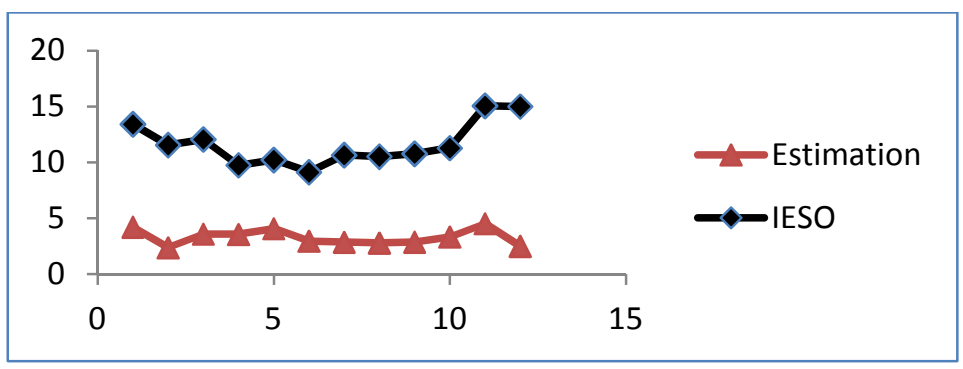

Figure 2: Hourly mean absolute errors (MAE) averaged over months: Our estimation versus IESO estimation: $x$-axis: months; $y$-axis: MAE.

Table 2: Summary statistics of hourly prices $(\$ / \mathrm{MWh})-$ actual realizations, model predictions, and IESO predictions between April 1, 2007 and March 31, 2008.

\begin{tabular}{|l|c|c|c|}
\hline & Actual & Model Prediction & IESO Prediction \\
\hline Average price & 47.16 & 49.95 & 55.38 \\
\hline Stdev & 25.21 & 26.37 & 25.59 \\
\hline Min price & -2.72 & -6.95 & 2.9 \\
\hline Max price & 563.62 & 572.58 & 193.87 \\
\hline Kurtosis & 29.18 & 26.06 & 0.48 \\
\hline Skewness & 2.49 & 2.37 & 0.68 \\
\hline
\end{tabular}

Table 2 shows that the distribution of our predicted prices (the lowest price (see Section 5.2 for the sources of negative prices), the highest price, kurtosis, skewness, and the standard deviation) is near the distribution of actual prices, confirming the high predictive power of the model. Our average hourly price for the year is $\$ 49.95$ and the actual average price is $\$ 47.16$. Hence, the model produces the average hourly equilibrium prices with $94.4 \%$ accuracy. Although the predicted average equilibrium price in the year is above the average actual price, 1456 hours out of 8784 hours $(17 \%)$ our hourly predicted market prices were below the actual market prices, and in the remaining times $(83 \%)$ our prices were above the market realizations. Also in Figure 3, we draw weekly actual and our predicted prices over the weeks, and it clearly shows how close our price predictions to the realizations. 


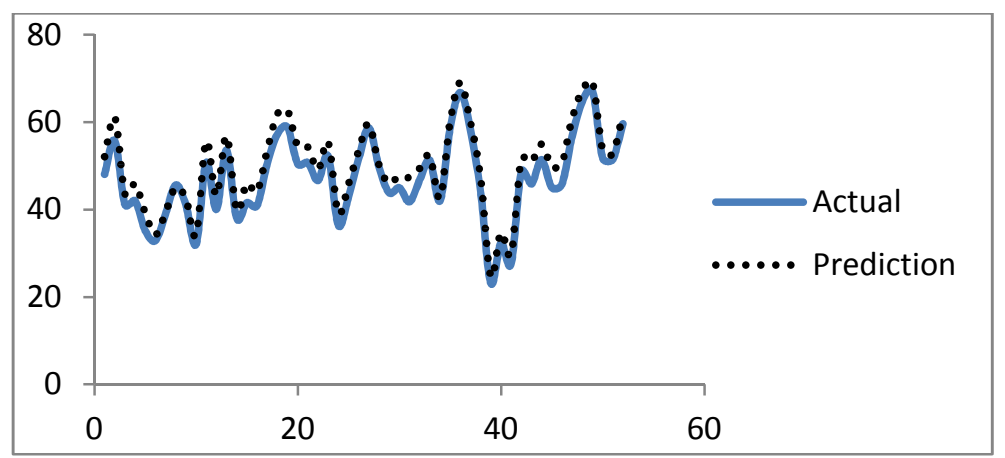

Figure 3: Weekly prices in $\$ / M W h-a c t u a l$ versus predictions; $x$-axis: weeks; $y$-axis: prices.

\subsection{Quantity Estimations}

Thus far we compared the price predictions; however the accuracy of the quantities is also important as they will determine firm productions and emissions. We will first compare our simulated demand/load quantities (or total outputs of the firms) to the operator's predictions. We will find that the outcomes are asymmetric: the operator overestimates, while we underestimate the quantities.

Throughout the year the average hourly demand estimates by the IESO and our model are 19,466 MWh, 18,210 MWh, resp. The actual mean load quantity is 18,966 MWh. Although our predicted average equilibrium load in the year is just $4 \%$ below the realization, 1451 hours out of 8784 hours $(16.5 \%)$ our predicted quantities are $2 \%$ above the actual demand quantities and in the remaining times $(83.5 \%$ of time) our load estimations are $5 \%$ below the market realizations. On the other hand, the system operator over-predicts the market demand quantities $92.5 \%$ of the time during which its predictions are 3\% above the realized load. The predicted standard deviations of the demand quantities are near the realized one: they are 2,645 and 2,461 MWh based on the operator and model predictions, resp., and the actual one is 2,639 MWh. The maximum market demand quantity in the year is 27,210 MWh. The predictions by the model and operator are 26,252 and 28,283 MWh, resp. The minimum consumption/load in the year is $12,807 \mathrm{MWh}$, and the predicted ones are 13,314 and $999 \mathrm{MWh}$ by the operator and the model, resp. Our minimum load prediction is low because there are times in which market prices are negative. In the case of negative market prices a classic Cournot model would predict zero supply, but our dominant firms with fringe suppliers model predicts positive supply. In the actual market operations, when the market prices are negative for any positive output power producers are paid positive prices by the operator because the production is costly, also importers are paid 
at least the price in the distant market where they are originated. However, customers (e.g., distribution companies or large industrial buyers) get paid to consume the good in the presence of negative market prices. As an outcome of the model, the dominant firms do not produce any output at the negative prices. The only supply comes from the imports and the fringe producers whose production capacity is low and they use their zero marginal cost hydro and wind generators during the negative price hours. Therefore, our minimum production estimation is positive but lower than the actual one.

When we compare the mean absolute errors for all hours in the year, the MAE between our estimations and the actual outputs is $872 \mathrm{MWh}$, and the MAE between the operator's estimation and the actual productions is $522 \mathrm{MWh}$, which suggests that on average operator's quantity predictions are better. However, in some months our model outperforms. For example, in March 2008 we predict $576 \mathrm{MWh}$ output differential between the model outputs and realizations, whereas the IESO predicted MAE is $624 \mathrm{MWh}$. However, the predicted MAE by the model and operator are small relative to the size of the actual total outputs in the market, which may suggest that the output predictions of the operator and the model are equally good.

To sum up, in price and quantity comparisons we find that our predictions are close to the actual prices, and the model reproduces hourly equilibrium prices with $94.4 \%$ accuracy and predicts the total output with 96\% accuracy. However, the following question naturally arises: which estimations should we care about the most? We argue that the price estimation will be more important in welfare analysis, and the output estimations will matter the most in emissions calculations. As we on average underestimate the quantities our emissions estimations may be providing lower bounds, which we will examine in detail in Sections 6 and 7. Since our price and quantity estimations are near the actual levels, depending on the shape of the actual demand and cost functions (which are not perfectly known by all market participants), our welfare predictions could be near the "actual" values.

\subsection{Firm Level Estimations}

In the above sections we show that total output and price predictions are near the actual outcomes. In the following figure, we will compare total (MWh) productions of firms to the model predictions in the year. We run the model every hour and obtain production outputs of the 
firms. We take the total hourly predicted and actual production quantities of the firms and juxtapose them in Figure 5.

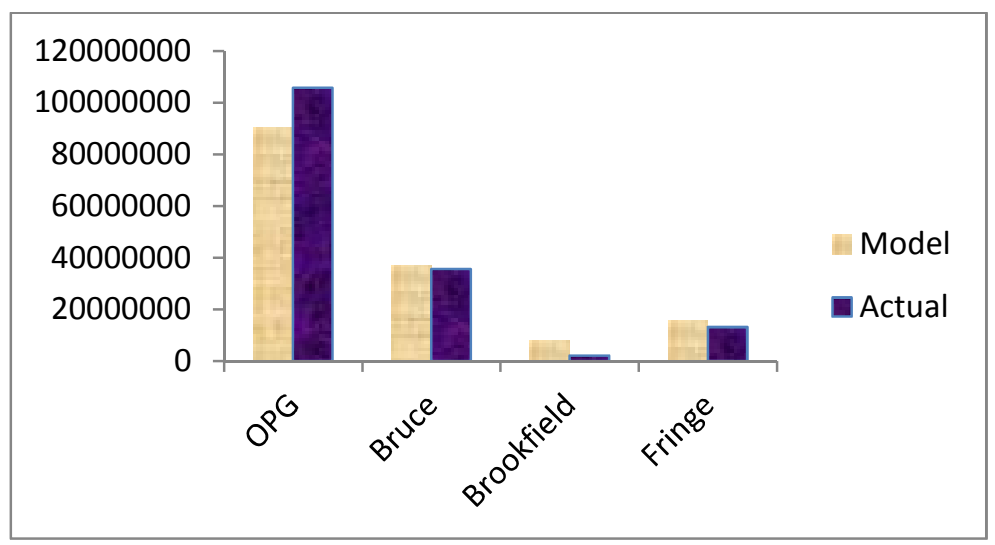

Figure 4: Actual versus predicted productions by firms (total MWh over the year).

Almost $84 \%$ of the total production comes from OPG and Bruce Nuclear. In comparing the equilibrium versus real outputs of the largest firm OPG, we find that the model predicts average hourly OPG production of 10,307 MWh versus real output of 12,055 MWh. OPG has nuclear, hydro, coal, oil and natural gas fired generators. The model predicts a profit maximizing level of output from coal and gas units lower than the actual production which mainly derives the discrepancy between OPG's actual and predicted total production. For other technologies predicted and actual production levels are very similar. The model predicts that Bruce Nuclear produces at the available production capacity every hour all year long, while the actual average hourly production is just $4 \%$ below the average available capacity.

The other dominant firm which is Brookfield Renewable Inc has hydro, wind and natural gas fueled generation stations. While the model's prediction for natural gas fired generators is close to the actual, actual production from renewable resources of hydro and wind is much lower than the model's profit maximizing levels. As a result average hourly predicted production for Brookfield is $914 \mathrm{MWh}$ versus the average real output of $252 \mathrm{MWh}$.

From Figure 4 we observe that model's fringe output is close the actual one. Small and independent firms (fringe suppliers) produce electricity from hydro, wind, biomass, and natural gas fueled generators. While the actual average hourly production is 1,507 MWh the model's prediction is $1,780 \mathrm{MWh}$. 
To sum up, although our predictions for the market and firm levels are close to the realizations and are overall better than the system operator's predictions ${ }^{25}$, we observe some differences at the firm/generator level productions, which can unsurprisingly be expected. The key difference in production stems from the allocation of hydro resources: profit maximization behavior leads to higher outputs from the hydropower generators than the actual outputs. However, in reality hydropower management is subject to certain production and regulatory constraints such as minimum reservoir capacity, maximum production capacity, ramp-up and ramp down rates, inflows, evaporation, leakage, and recreational and irrigational constraints, as well as other technical constraints germane to hydropower dams. On top of these constraints, dynamic intertemporal considerations regarding how to allocate variable stock of water under uncertainty over time affect the actual productions. Generally, these constraints are incorporated into the detailed models of hydropower management where optimum water allocation of a regulated hydro producer is examined. Our model has not considered these constraints for the sake of simplicity; hence differences between optimum versus actual hydro outputs have arisen, which in turn have affected distribution of outputs from other technologies such as underestimation of coal-fired production. In terms of nuclear generators the model prediction is very close to the actual. Importantly, while nuclear generators can technically produce at the capacity in actual data there is some variation in productions/available capacities across days, as well as during the hours of a day. These indicate the limited flexibility of the nuclear power producer and how it adjusts its output and available capacity with respect to the changing market conditions. ${ }^{26}$

On top of the above issues, there are other system-wide constraints that can affect the actual allocation and outputs of generators. One of them is the congestion constraints that could restrain the production from certain generators to ease the transmission network. Even though the generators are available and scheduled to produce the last minute calls can cause some generators to produce less and some to produce more, or others get totally cancelled so as to match demand to supply and maintain the optimal power flow on the grid. Also, actual operations are subject to uncertainties on both supply and demand sides. A generator scheduled

\footnotetext{
${ }^{25}$ The Independent System Operator makes prediction only at the market level (clearing prices and quantities), and does not make firm level production predictions nor does it at the firm's generators level.

${ }^{26}$ The nuclear available capacity can be affected by the IESO's action to deal with Surplus Baseload Generation condition, in which the IESO keeps a nuclear unit to a low production level for a few hours. The nuclear capacity can also be affected by outages/deratings because of technical difficulties at the plant.
} 
to produce may cancel its production at the last minute due to a failure in generation process, or a customer may wish to withdraw more electricity due to a sudden increase in consumption. Less importantly, there are also generation units that do not participate into the market operations. They are called "exempt and non-market generators" which are independent and produce electricity to meet certain local demand and/or export their production elsewhere. For instance, if they increase their exports, then they may influence market participating generators' exports, which may affect the total market demand (Ontario demand plus exports) and in turn the supply of market generators.

Moreover, our modeling assumptions can create differences between the actual and observed outcomes. We assumed a certain competition structure which could be different in the real world. The profit maximization assumption is defensible; however some generators owned by firms could be subject to a rate of return regulation. We assumed a simple demand structure along with smoothed cost curves. We ignored the non-convexities in the generation process along with startup and shut down costs, and ramp-up and ramp-down rates. We assumed firms dispatch generators in a least costly manner; however this might not be true in the presence of fixed charges/costs.

Consequently, these events and some of the modeling assumptions can explain the firm level discrepancies between the actual and model outcomes.

\section{Welfare Analysis}

The welfare implications of electricity trade have not been addressed before, although trade is an important component of the wholesale electricity operations. Also, a concern of market observers in power markets is the existence of negative wholesale prices and their impact on the welfare. In this section we will also measure the welfare loss when the market prices happen to be negative.

Our welfare measures in Ontario include values assessed for air pollution, in particular SO2 and NOx emissions. Because the SO2 and NOx emissions are regulated and firms purchase emission permits, the social costs of these emissions are internalized by the power producers, and hence the impact of pollution abatements are already included in welfare (consumer and producer 
surplus) calculations. However, the $\mathrm{CO} 2$ emissions are one of the unregulated emissions and will constitute a social cost, which is not accounted for in our total surplus computations.

\subsection{Welfare Gain from Imports}

We compute and compare the welfare loss (dead weight loss, DWL) with respect to change in import quantities in Ontario. Hourly import quantities are highly variable and traders and generation owners import (and export) electricity depending on the price expectations in the local and distant markets. For a given hour we run our competition model at the actual import levels and obtain the equilibrium production levels of generators (and firms) and the market price. After updating demand, import, available production capacities, and production cost functions, we re-run the model to make market predictions for the next hour, and compute the hourly DWL at the actual import levels $(\mathrm{I}=\mathrm{I})$. To measure welfare change with respect to change in import levels we examine market outcomes in two counterfactual scenarios/policies: in the absence of imports $(\mathrm{I}=0)$ and in the presence of imports doubling $(\mathrm{I}=2 \mathrm{I})$. The scenario that covers no imports $(\mathrm{I}=0)$, the autarky situation, is a polar case for a closed wholesale electricity market which does not import from the neighboring jurisdictions. The Ontario interconnection capacity (with New York, Michigan, Minnesota, Manitoba and Quebec markets) for imports is around 5991 MW (see IESO, 2009a), and the realized maximum total import quantity between April 2007 and March 2008 was $2808 \mathrm{MWh}$, and 99\% of the time (in all hours) the total Ontario import was below $2000 \mathrm{MWh}$, which is less than half of the actual import capability. Therefore, our counterfactual scenario that imports double $(\mathrm{I}=2 \mathrm{I})$ is a feasible exercise and obeying the interconnection capacity constraints.

Alternatively, $\mathrm{I}=0$ could be as a result of production capacity investments in the home market in which there is an excess production which will be exported only and hence no imports are required. I=2I could be due to transmission investments between the home market and neighbouring jurisdictions such that new transmission capacity will entail meeting high demand in the home market. Indeed the key limitation in electricity exchange is the capacity of transmission lines (see Wolak, 2012), and the transmission investments has increased since 2002 to facilitate higher volume trade activities between Ontario and the neighbouring markets.

The intersection of the hourly system marginal cost (SMC) curve and the hourly demand function gives rise to the efficient market price and quantity. The SMC is the horizontal 
summation of firms' marginal cost curves. Since firms' marginal cost curves change every hour, due to the available capacities, the SMC curve changes hourly. Electricity demand also changes every hour. To calculate the welfare loss we compare the efficient outcomes with the predicted market prices and the outputs. Every hour we run the model for each import scenario- no imports $(\mathrm{I}=0)$, imports at the realized levels $(\mathrm{I}=\mathrm{I})$, and imports twice the realized levels $(\mathrm{I}=2 \mathrm{I})-$ to figure out the equilibrium outcomes. Given the hourly system marginal cost curve and the predicted market prices and demand quantities, we compute the welfare loss for each import scenario $\mathrm{I}=0, \mathrm{I}=\mathrm{I}$, and $\mathrm{I}=2 \mathrm{I}$. In Table 3, we report DWL and observe that the welfare loss is a decreasing function of the imports. The welfare loss reduces $34.69 \%$ from zero imports to the imports at the current levels. If the imports were doubled for all hours, the welfare loss would further reduce $34.66 \%$, from $\$ 342.1$ million to $\$ 223.5$ million dollars. Average hourly market prices over the year decrease as the imports increase, so does the price volatility. As the prices decrease and the demand quantities increase, the welfare gain improves.

Given that the demand curve and the SMC stay the same under each import scenario, the change in welfare from a policy change (i.e., the change in import scenarios) can be measured by the change in DWL. The yearly welfare gain from no imports $(\mathrm{I}=0)$ to the imports at the current levels ( $\mathrm{I}=\mathrm{I})$ will be $\$ 181.7$ million dollars, which is the wealth consumers and producers enjoy. Alternatively, instead of importing at the current levels if there would not be any imports, the welfare loss would be $\$ 181.7$ million dollars more $\left(\mathrm{DWL}_{\mathrm{I}=0}-\mathrm{DW} \mathrm{L}_{\mathrm{I}=\mathrm{I}}\right)$. If the scenario would involve twice the current import levels $(\mathrm{I}=2 \mathrm{I})$, then the change in welfare gain would be further 118.6 million dollars $\left(\mathrm{DWL}_{\mathrm{I}=\mathrm{I}}-\mathrm{DWL}_{\mathrm{I}=2 \mathrm{I}}\right)$.

Table 3: Welfare loss, average prices and demand quantities with respect to change in imports.

\begin{tabular}{|l|l|l|l|}
\hline Month / Import level & $\mathrm{I}=0$ & $\mathrm{I}=\mathrm{I}$ & $\mathrm{I}=2 \mathrm{I}$ \\
\hline 4.2007 & $41,190,907$ & $34,886,200$ & $29,340,601$ \\
\hline 5.2007 & $33,446,595$ & $21,9444,250$ & $15,937,581$ \\
\hline 6.2007 & $41,238,427$ & $30,384,794$ & $22,124,856$ \\
\hline 7.2007 & $43,544,893$ & $33,704,343$ & $25,901,664$ \\
\hline 8.2007 & $58,898,609$ & $42,999,625$ & $29,935,979$ \\
\hline 9.2007 & $37,994,417$ & $21,745,963$ & $12,812,450$ \\
\hline 10.2007 & $38,772,448$ & $24,495,167$ & $15,359,506$ \\
\hline
\end{tabular}




\begin{tabular}{|l|c|l|l|}
\hline 11.2007 & $32,220,239$ & $17,004,178$ & $8,772,313$ \\
\hline 12.2007 & $53,928,739$ & $32,975,145$ & $17,254,768$ \\
\hline 1.2008 & $35,334,372$ & $19,176,444$ & $10,302,456$ \\
\hline 2.2008 & $53,475,813$ & $34,918,621$ & $21,992,323$ \\
\hline 3.2008 & $53,818,528$ & $27,913,605$ & $13,815,287$ \\
\hline & & & \\
\hline Total DWL (\$) & $523,883,988$ & $342,148,334$ & $223,549,784$ \\
\hline Change in Welfare (\$) & - & $181,735,654$ & $118,598,550$ \\
\hline $\begin{array}{l}\text { Price (\$) } \\
\text { Average price }\end{array}$ & 52.84 & 49.95 & 47.24 \\
\hline $\begin{array}{l}\text { St. dev. } \\
\text { Demand quantity (MWh) } \\
\text { Average demand } \\
\text { St. dev }\end{array}$ & 29.5 & 26.37 & 24.69 \\
\hline
\end{tabular}

Note that the deadweight loss (loss of producer and consumer surplus) calculations in Table 3 already include the social cost of SO2 and NOx. However, it omits the externality cost of CO2 as it is free to emit and unregulated in Ontario.

The relationship between imports and welfare loss over the months is monotonic. However, this relation does not hold for all hours. For instance, at hour 18 of March 7, 2008, the DWL increases as the imports double. On the same day at hours 17 and 19, welfare loss always decreases in imports. The DWL is $\$ 13,078$ at hour 18 . However, when the imports double the DWL skyrockets to $\$ 170,260$. In Figure 5, we plot this situation. The competitive price and quantity we predict for hour 18 is $\left(\mathrm{p}_{\mathrm{c}}, \mathrm{q}_{\mathrm{c}}\right)=(77.16,24018.5)$. The equilibrium price and demand quantity pair at the present import level $(\mathrm{I}=2980 \mathrm{MWh})$ is $\left(\mathrm{p}_{\mathrm{I}}, \mathrm{q}_{\mathrm{I}}\right)=(83.89,22976.1)$. The equilibrium outcome when imports double to $(2 \mathrm{I}=5960 \mathrm{MWh})$ is $\left(\mathrm{p}_{2 \mathrm{I}}, \mathrm{q}_{2 \mathrm{I}}\right)=(73.14,24637.9)$. The DWL when $\mathrm{I}=\mathrm{I}$ is represented in the dark area, and it is the light area when imports double to 2I. The equilibrium price in the case of 2I is lower than the competitive price, $p_{c}>p_{2 I}$. This is not surprising because prices can even be negative (see Table 2). Note that the output is higher than the available production capacity $\mathrm{K}_{\mathrm{h}=18}$, which is equal to $24,550 \mathrm{MW}$, that is $\mathrm{q}_{2 \mathrm{I}}>\mathrm{K}_{\mathrm{h}=18}$. This production capacity varies over time due to the availability of generators, and the difference between the actual output and available production capacity can come from spinning reserves (backup generators), which are comprised of high-cost production technologies that run all the 
time to balance demand and supply in the case of supply disruptions and/or unexpected high demand conditions. The output higher than the available capacity provided by the spinning reserves should be priced at the price cap or maximum willingness to pay price $\mathrm{P}$, which is set to be $\$ 2,000 \mathrm{MWh}$ in the Ontario market, which contributes to a high welfare loss. Nevertheless, the DWL calculated at hour 18 should be the upper bound of the loss, if the backup generators are paid a price above the market clearing price in that hour. A policy implication of this result is that the DWL would go down if the regulators would set a lower price cap.

Increase in the DWL due to the increase in imports is a very rare situation in the case of imports doubling from the current levels. In our study period, this phenomenon occurs only $3 \%$ of the time; that is only 264 hours out of 8784 hours in the year. This happens only when the actual output exceeds the available production capacity of the firms. In the rest of the time, $97 \%$ of the time, increase in imports reduces the welfare loss, and the change in welfare loss over the months and in the year are reported in Table 3 .

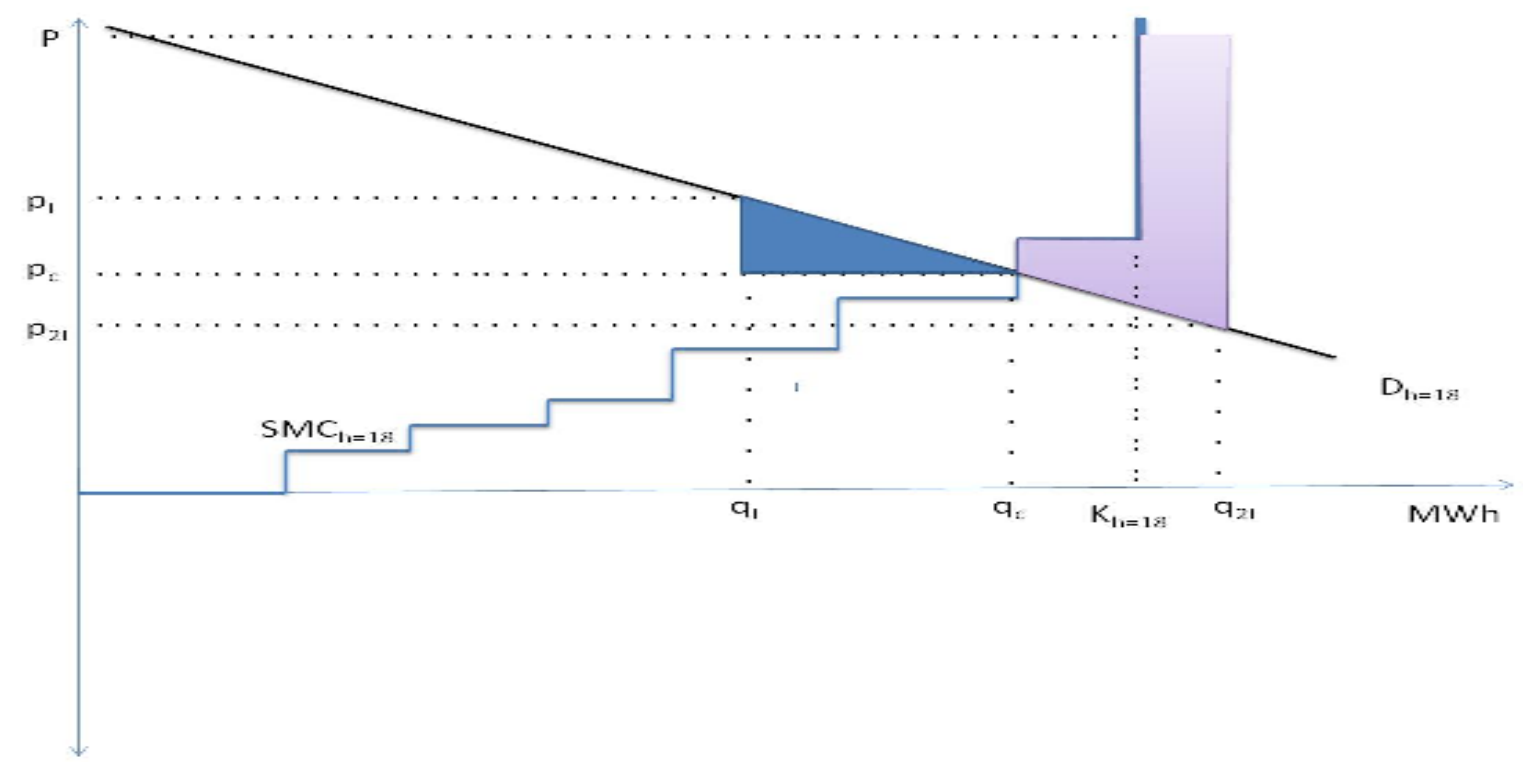

Figure 5: Welfare loss at hour 18 of March 7, 2008 when production is above the announced available capacity.

Most of the price-quantity pairs fall into the region in which prices are above the efficient levels and the outputs are lower than the competitive outputs. Consequently, the DWL is mostly represented by the triangle (dark area) in the figure. 


\subsection{Welfare Loss When Market Prices are Negative}

The spot market prices are negative during certain trading hours of the study period. Negative prices which are commonly observed in the wholesale electricity markets indicate not only that the wholesale electricity is free but also that buyers (e.g., distribution companies) are paid to consume electricity. Due to the "excess production" injection to the transmission grid, the lines get stressed and they should be relived, otherwise system-wide problems such as black-outs could occur. In case of negative prices, producers do not make any payments to the buyers but the system/market operator, who is responsible for electricity network security and reliability, often makes the payments to the buyers. The negative prices are rare and occurred only for 5 hours out of 8784 times in the year. It is a concern for some market observers (such as the market surveillance committee) that negative prices can distort the market and create DWL. To address this interesting case, we measure the welfare loss when prices are negative. We find that the welfare loss during negative prices is much lower than the average welfare loss created in hours at which firms exercise market power.

In Table 4 we present the hours of negative prices, actual imports and exports, price-quantity realizations, and our DWL estimates. The DWL calculations are done only at the actual import levels. Interestingly, the negative prices, which are small relative to the average daily/weekly/monthly/yearly prices, occurred only in the midnight off-peak period hours (hours 1 through 5). The exports (E) on average exceeded the import levels (I) in these hours at which prices are near zero but negative, and the demand quantities are lower than the average daily quantities.

The total DWL in the year is $\$ 342,148,334$ (in the Table 3), and the total DWL during negative prices is $\$ 54,310$. Therefore, the DWL during negative prices is just $0.016 \%$ of the total welfare loss.

Table 4: Negative prices, market outcomes, and the welfare loss.

\begin{tabular}{|c|llccc|}
\hline Time & $\mathrm{P}(\$ / \mathrm{MWh})$ & $\mathrm{Q}(\mathrm{MWh})$ & $\mathrm{I}(\mathrm{MWh})$ & $\mathrm{E}(\mathrm{MWh})$ & $\mathrm{DWL}(\$)$ \\
\hline $9.18 .07, \mathrm{~h}=1$ & -0.4 & 14,130 & 1,107 & 815 & 8,219 \\
\hline $2.18 .08, \mathrm{~h}=2$ & -1.91 & 15,553 & 927 & 973 & 12,572 \\
\hline
\end{tabular}




\begin{tabular}{|c|ccccc|}
\hline $2.18 .08, \mathrm{~h}=3$ & -2.72 & 15,454 & 975 & 1047 & 13,363 \\
\hline $2.18 .08, \mathrm{~h}=4$ & -1.39 & 15,530 & 954 & 990 & 11,060 \\
\hline $2.18 .08, \mathrm{~h}=5$ & -0.65 & 15,628 & 802 & 1150 & 9,096 \\
\hline
\end{tabular}

\section{Air Emissions Offset by Imports}

It is assumed that imports should reduce the market prices, a result that a quantity competition model can predict. However, in reality the rate at which imports affect the prices and whether imports cause any reductions in the emissions have not been addressed. The answer for whether imports abate emissions in a local market is not obvious because of the following reasons. A key issue is what generators imports would displace; dirtier or cleaner technologies. If the imports are displacing dirtier local generators, then they can cause emission reductions. If the imports displace expensive and relatively cleaner generators (like natural gas-fired generators), then the low cost and dirtier technologies (like coal-fired generators) can increase their production to meet (high) demand and compete with cheap imports. This can cause rising carbon emissions. Note that in a Cournot competition model generation units are used in merit order so as to minimize production costs. Moreover, in the real market generators may select their available production capacities strategically to respond to rival firm production quantities and hence which generator is replacing which may not be clear.

Note that the same production technologies could have different production characteristics such as different heat rates and emission rates. For example, a firm, say OPG, produces electricity from coal plants A and B at a given hour. Assume Plant A releases more emissions than Plant B due to the age factor, and the production cost of Plant B is higher than that of Plant A. Suppose that the scheduled import quantity will rise for the next hour. Given the same production from other generators in the market, OPG could reduce the production from Plant B and increase the production from Plant A as a response to increase in import level, and cause more air pollution. If, however, the reverse applies, that is in the next hour scheduled import reduces, then production from Plant B might increase (and production from Plant A might strategically go down) and hence the total emissions would go down. 
Alternatively, assume that a coal plant is the marginal production technology. If the scheduled import increases for the next hour, the emissions will reduce as the imports will displace some of the coal production. Hence, the inverse relationship between imports and emissions can occur.

Also, the imports that replace the cleaner and expensive technologies could cause market price reductions as the expensive production technologies are avoided. This can in turn lead to increased electricity consumption which can increase emissions, which is called "rebounding effect". While we quantify the relationship between imports and market prices in the model, we also measure the change in emissions with respect to the change in import scenarios. In Table 5, we report equilibrium pollution levels ( $\mathrm{CO} 2, \mathrm{NOx}, \mathrm{SO} 2)$ over months, obtained by summing over the hourly equilibrium pollution quantities of generators, by the type -biomass, coal, natural gas and oil- of fuels ${ }^{27}$ as import levels change.

While NOx and SO2 emissions have significant local impacts, hence concerning mostly Ontario, $\mathrm{CO} 2$ differs from these emissions as its environmental impact is global through diffusion causing GHG effects. However, CO2 emissions are also important locally because Ontario has commitments to the federal government, which has to meet its emission targets globally, in reducing its GHG emissions.

The pollution levels are in ton and the first row of pollution quantities refer to the equilibrium levels when there is no imports $(\mathrm{I}=0)$, the second row represents the pollution amounts at the actual import levels $(\mathrm{I}=\mathrm{I})$, and the third row denotes the amounts when imports double (I=2I). For each month, pollution levels reduce as

Table 5: Emission levels in ton by technology with respect to change in import scenarios.

\begin{tabular}{|c|c|c|c|c|c|c|c|c|c|c|}
\hline \multirow{2}{*}{$\begin{array}{l}\text { Import } \\
\text { Level }\end{array}$} & \multirow[t]{2}{*}{ Date } & \multicolumn{3}{|c|}{ COAL } & \multicolumn{3}{|c|}{ NATURAL GAS/OIL } & \multicolumn{3}{|c|}{ BIOMASS } \\
\hline & & NOx & SO2 & $\mathrm{CO} 2$ & NOx & SO2 & $\mathrm{CO} 2$ & NOx & $\mathrm{SO} 2$ & $\mathrm{CO} 2$ \\
\hline $\mathrm{I}=0$ & 4.2007 & 608 & 2,091 & 871,311 & 519 & - & 600,661 & 123 & - & 22,812 \\
\hline$I=1$ & & 551 & 1,857 & 798,811 & 507 & - & 589,274 & 123 & - & 22,811 \\
\hline \multirow[t]{3}{*}{$\mathrm{I}=2 \mathrm{I}$} & & 498 & 1,636 & 720,704 & 494 & - & 577,452 & 123 & - & 22,810 \\
\hline & 5.2007 & 443 & 2,020 & 662,731 & 428 & - & 532,050 & 118 & - & 21,738 \\
\hline & & 352 & 1,667 & 574,171 & 409 & - & 514,259 & 118 & - & 21,738 \\
\hline
\end{tabular}




\begin{tabular}{|c|c|c|c|c|c|c|c|c|c|}
\hline & 282 & 1,353 & 485,565 & 394 & - & 499,667 & 118 & - & 21,737 \\
\hline \multirow[t]{3}{*}{6.2007} & 853 & 3,378 & $1,152,592$ & 461 & - & 566,342 & 118 & - & 21,885 \\
\hline & 701 & 2,907 & $1,028,637$ & 446 & - & 553,459 & 118 & - & 21,882 \\
\hline & 556 & 2,424 & 895,529 & 432 & - & 539,963 & 118 & - & 21,879 \\
\hline \multirow[t]{3}{*}{7.2007} & 898 & 3,559 & $1,230,422$ & 477 & - & 590,476 & 128 & - & 23,610 \\
\hline & 761 & 3,096 & $1,107,181$ & 462 & - & 577,355 & 128 & - & 23,609 \\
\hline & 636 & 2,648 & 979,413 & 447 & - & 563,610 & 128 & - & 23,608 \\
\hline \multirow[t]{3}{*}{8.2007} & 1,685 & 5,793 & $1,906,448$ & 610 & - & 710,292 & 122 & - & 22,488 \\
\hline & 1,423 & 5,046 & $1,721,124$ & 594 & - & 695,985 & 122 & - & 22,487 \\
\hline & 1,186 & 4,359 & $1,540,729$ & 577 & - & 680,184 & 122 & - & 22,486 \\
\hline \multirow[t]{3}{*}{9.2007} & 1,316 & 3,936 & $1,406,181$ & 507 & - & 604,674 & 126 & - & 23,290 \\
\hline & 1,036 & 3,153 & $1,193,825$ & 478 & - & 578,458 & 126 & - & 23,284 \\
\hline & 789 & 2,464 & 986,799 & 446 & - & 550,592 & 126 & - & 23,277 \\
\hline \multirow[t]{3}{*}{10.2007} & 1,134 & 4,324 & $1,311,973$ & 580 & - & 657,376 & 129 & - & 23,833 \\
\hline & 959 & 3,729 & $1,163,465$ & 551 & - & 630,935 & 129 & - & 23,806 \\
\hline & 752 & 2,971 & 968,870 & 520 & - & 603,484 & 129 & - & 23,777 \\
\hline \multirow[t]{3}{*}{11.2007} & 1,208 & 4,946 & $1,451,788$ & 603 & - & 676,899 & 115 & - & 21,320 \\
\hline & 885 & 3,966 & $1,216,473$ & 556 & - & 637,331 & 115 & - & 21,317 \\
\hline & 629 & 2,947 & 962,604 & 506 & - & 595,699 & 115 & - & 21,309 \\
\hline \multirow[t]{3}{*}{12.2007} & 1,191 & 4,037 & $1,214,099$ & 591 & - & 674,352 & 134 & - & 24,683 \\
\hline & 876 & 3,106 & 976,753 & 557 & - & 645,125 & 134 & - & 24,674 \\
\hline & 654 & 2,345 & 767,640 & 518 & - & 611,005 & 133 & - & 24,661 \\
\hline \multirow[t]{3}{*}{1.2008} & 733 & 3,019 & 986,662 & 433 & - & 555,839 & 129 & - & 23,792 \\
\hline & 573 & 2,274 & 772,262 & 399 & - & 525,438 & 129 & - & 23,780 \\
\hline & 447 & 1,593 & 557,027 & 365 & - & 493,616 & 129 & - & 23,766 \\
\hline \multirow[t]{3}{*}{2.2008} & 840 & 3,122 & $1,038,307$ & 566 & - & 660,812 & 123 & - & 22,787 \\
\hline & 658 & 2,427 & 841,753 & 537 & - & 636,406 & 123 & - & 22,778 \\
\hline & 523 & 1,810 & 647,010 & 504 & - & 608,630 & 123 & - & 22,765 \\
\hline \multirow[t]{3}{*}{3.2008} & 1,246 & 4,297 & $1,478,850$ & 652 & - & 750,396 & 136 & - & 25,044 \\
\hline & 888 & 3,136 & $1,162,280$ & 596 & - & 705,140 & 136 & - & 25,044 \\
\hline & 649 & 2,131 & 834,000 & 538 & - & 655,698 & 136 & - & 25,044 \\
\hline
\end{tabular}

import quantities increase and imports displace possible supply from the dirty technologies. Natural gas and biomass fueled generators are relatively clean and do not emit SO2, however SO2 levels stemming mainly from coal plants decrease nonlinearly as import levels vary linearly. Highest levels of GHG emission (in this case, CO2) emanates mainly from coal generators and then from natural gas/oil-fueled generators. The rate of decrease of $\mathrm{CO} 2$ quantities as a result of increase in imports is higher for the coal generators than the natural gas/oil generators. $\mathrm{CO} 2$ 
emissions from the biomass technologies are pretty stable across the import levels; the reason is associated with the low production costs as they run as much as possible.

The variation in $\mathrm{CO} 2$ emissions from coal plants across the periods is higher than the $\mathrm{CO} 2$ emission variations in other technologies (biomass and gas/oil). Variations of SO2 and NOx emissions in coal plants are also higher than the variations of the very same pollutants in the natural gas/oil and the biomass plants. This is mainly due to the high variability of the outputs of the coal generators. Pollution levels of coal plants during high demand months of summer (JuneSeptember) and winter (January-March) are greater than the pollution levels in low demand periods. We do not observe the same exact pattern of pollutions from the other production technologies. For example, the pollution levels of biomass technologies seem relatively constant across the periods.

In the following table, Table 6, we report equilibrium pollution quantities over players with respect to the change in import levels. The least polluting player is the Brookfield Renewable Energy, and the most polluting player is the OPG. The OPG is a dominant player serving more than half of the demand, and has large hydro and nuclear units in production. The fringe players meet around $10 \%$ of the load and has mainly natural gas and oil fired production technologies. Despite their low share in total demand they contribute a much larger fraction of the total emissions due to their dirty technologies. SO2 pollution is mainly due to the OPG as it is the only firm operating coal plants. ${ }^{28}$ Increase in the import levels has greater impacts on the OPG pollution levels than the rest of the players such that the emission levels of NOx, SO2 and the $\mathrm{CO} 2$ drops over $15 \%$ as the import quantities double (from $\mathrm{I}=0$ to $\mathrm{I}=\mathrm{I}$ and to $\mathrm{I}=2 \mathrm{I}$ ). The emissions by fringe players also moderate as a result of trade, but the reduction is less pronounced relative to the emissions of the OPG. Note that the Brookfield emissions are constant over import scenarios as its small capacity gas-fired production constraint is binding.

Table 6: Equilibrium emission levels in tons over firms as import levels vary.

\section{OPG BROOKFIELD FRINGE}

\footnotetext{
${ }^{28} \mathrm{SO} 2$ rates of gas/oil-fired generators are negligible and hence their $\mathrm{SO} 2$ emissions are ignored parallel with the literature.
} 


\begin{tabular}{|llrcc|}
\hline $\mathbf{I}=\mathbf{0}$ & NOx & 12,154 & 312 & 7,614 \\
& SO2 & 44,521 & 0 & 0 \\
& CO2 & $14,711,363$ & 283,247 & $7,574,204$ \\
\hline $\mathbf{I}=\mathbf{I}$ & NOx & 9,662 & 312 & 7,280 \\
& SO2 & 36,364 & 0 & 0 \\
& CO2 & $12,556,733$ & 283,247 & $7,283,127$ \\
\hline $\mathbf{I = 2 I}$ & NOx & 7,599 & 312 & 6,928 \\
& SO2 & 28,681 & 0 & 0 \\
& CO2 & $10,345,889$ & 283,247 & $6,973,473$ \\
\hline
\end{tabular}

Table 7 summarizes how the equilibrium total emission levels change as a result of change in trade levels. It is clear that $\mathrm{CO} 2$ emissions are the largest among other gasses. Given that $\mathrm{CO} 2$ is comprised of $80 \%$ of GHG emissions, it becomes clear how trade could improve the air quality. A policy implication is to necessitate $\mathrm{CO} 2$ emission markets coupled with a cap-and-trade type environmental protection program, if the electricity trade is not a viable option across jurisdictions. SO2 amounts approximately drops $21 \%$ as the imports double from I to 2I. The reduction in NOx levels is around $14 \%$ when the import quantities double, and the $\mathrm{CO} 2$ reduction is around $13 \%$.

Table 7: Total emissions in tons with respect to change in import levels

\begin{tabular}{|llll|}
\hline $\mathbf{I}=\mathbf{0}$ & NOx & SO2 & CO2 \\
$\mathbf{n y y y} \mathbf{I = I}$ & 20,080 & 44,521 & $22,568,814$ \\
$\mathbf{I = 2 \mathbf { I }}$ & 17,254 & 36,364 & $20,123,107$ \\
& 14,839 & 28,681 & $17,602,609$ \\
\hline
\end{tabular}

Based on the equilibrium emissions levels in Table 7 we can calculate the average emission savings with respect to the change in import levels. Specifically, we compute that $0.62 \mathrm{lbs}$ of NOx, $1.99 \mathrm{lbs}$ of SO2, and 0.3 tons of $\mathrm{CO} 2$ are avoided per MWh import increase (from I=I to $\mathrm{I}=2 \mathrm{I}$ ) in Ontario in the year. Nevertheless, the decrease in imports (from $\mathrm{I}=\mathrm{I}$ to $\mathrm{I}=0$ ) will exhibit different emissions changes. Namely, one MWh import reduction will on average result in 0.73 lbs of NOx, $2.11 \mathrm{lbs}$ of SO2, and 0.29 tons of $\mathrm{CO} 2$ emissions increases. The rates of change of emissions with respect to the imports exhibit different magnitudes depending on whether imports increase or decrease. This is mainly due to the change in compositions of production technologies with respect to the change in import conditions in equilibrium. 
In Figure 6, we plot average $\mathrm{CO} 2$ emissions per hour by the hour of the day for various import scenarios. The dashed line represents the amount of $\mathrm{CO} 2$ at the current import levels $\mathrm{I}=\mathrm{I}$. As the import levels increase from I to 2I (or from 0 to I) the emissions decrease monotonically. The emitted $\mathrm{CO} 2$ levels are the highest during the peak hours of the day and the lowest during the midnight hours. The impact of imports, measured as the largest emission reductions, from $\mathrm{I}=0$ to $\mathrm{I}=\mathrm{I}$ (or from $\mathrm{I}=\mathrm{I}$ to $\mathrm{I}=2 \mathrm{I}$ ) on the $\mathrm{CO} 2$ levels are more pronounced through $7 \mathrm{am}-21 \mathrm{pm}$ than the rest of the off-peak periods. That is, the imports are the most valuable through hours $7 \mathrm{am}-21 \mathrm{pm}$ and indeed this is the time frame in which we observe highest import levels in the market. During these hours the average emission reduction from no imports to imports (or from imports to twice the imports) is around $11 \%$. For the rest of the periods the import levels are low, and the change in imports has a small absolute effect in the $\mathrm{CO} 2$ emission reductions.

Figure 6: Average hourly $\mathrm{CO} 2$ emissions in ton (y-axis) by the hour of the day (x axis).

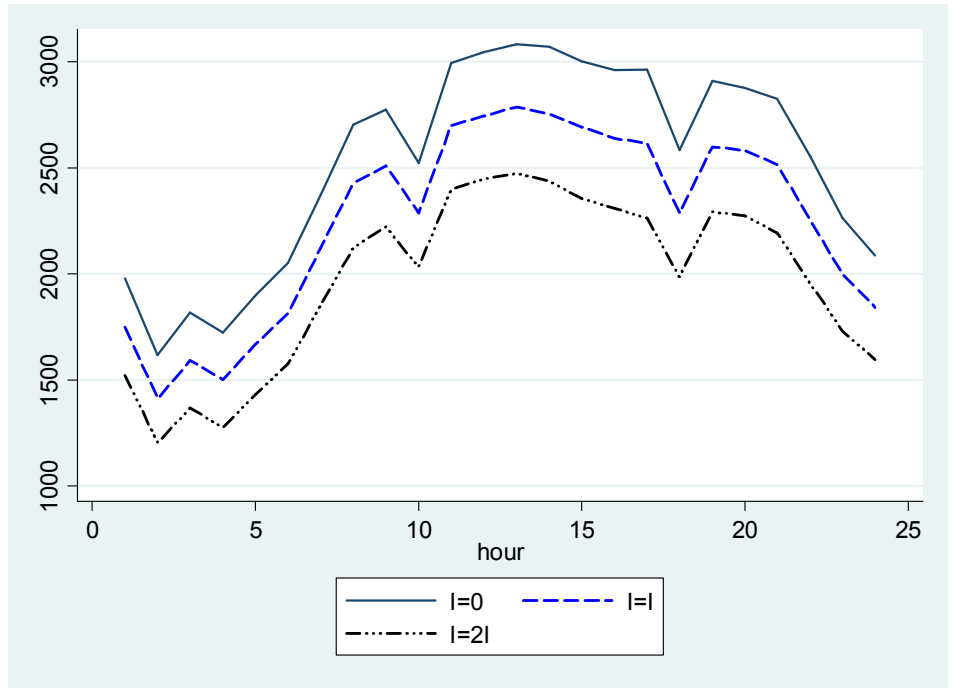

The distributions of the NOx and $\mathrm{SO} 2$ emissions over hours (reported in the Appendix, Figures A7 and A8) are very similar to that of $\mathrm{CO} 2$ emissions where main emissions occur during the peak times. For $\mathrm{SO} 2$ average reduction in the emissions is about $18 \%$ from no imports $(\mathrm{I}=0)$ to imports ( $\mathrm{I}=\mathrm{I}$ ) (it is about $21 \%$ from $\mathrm{I}$ to $2 \mathrm{I}$ ) in all hours. For NOx average reduction in the emissions is about $14 \%$ from no imports $(\mathrm{I}=0)$ to imports $(\mathrm{I}=\mathrm{I})$ and also, the same from $\mathrm{I}$ to $2 \mathrm{I}$ in all hours.

\section{Extension: The Role of Exports}


Hitherto we have mainly examined the role of imports on market outcomes and air emissions. Explicit analysis of exports has been omitted because exports are implicitly modeled in the total market demand formulation which is equal to Ontario demand plus export demand. However, it could be of interest to examine how a change in export demand would affect the firms' productions, market prices, and emissions levels. We will fix the imports at the existing hourly quantities and examine certain export scenarios to measure their impact in the market.

The treatment of exports in the market model is as follows. The inverse demand curve is, as is in Section 3, $p(t)=a_{t}-b_{t} Q_{t}, t=1,2, \ldots, T$, and the market demand is $Q_{t}(p)=\frac{a_{t}}{b_{t}}-\frac{p}{b_{t}}$ which incorporates both Ontario demand and actual exports at time $t$. Market supply is equal to $Q_{t}^{D}(p)+S_{t}(p)+I_{t}$, where $Q_{t}^{D}(p)$ is the aggregate supply of dominant firms, $S_{t}(p)$ is the fringe firms' supply, and $I_{t}$ is the actual imports at time $t$. Given the affine approximation for the fringe supply, $S_{t}(p)=f_{t}+g_{t} p$, and the market condition that demand must be met at all times, the equilibrium is $\frac{a_{t}}{b_{t}}-\frac{p}{b_{t}}=Q_{t}^{D}(p)+f_{t}+g_{t} p+I_{t}$. The change in export levels at a given time can be incorporated into the left hand side of this equilibrium condition to measure the change in production quantities and hence emissions released by all players. Denote $E_{t}$ as the export level at time $t$. To be consistent with the import analysis, we will examine three export scenarios: no exports, actual exports, and twice the actual exports. Given these exports scenarios we re-write the total market demand as $\frac{a_{t}}{b_{t}}-\frac{p}{b_{t}}+E_{t}$, where $E_{t}$ takes one of the three values depending on the export scenario. $E_{t}=0$ implies the current market scenario where export is at the existing level at hour $t$, because the market demand $Q_{t}(p)$ already incorporates actual export. $E_{t}=E_{t}$ means exports are twice the actual levels for all hours: it doubles because the market demand $\frac{a_{t}}{b_{t}}-\frac{p}{b_{t}}$ already includes the actual export and we add the same quantity to the existing level. Finally, $E_{t}=-E_{t}$ corresponds to no exports: we subtract the existing export from the market demand for each hour. With the presence of an export scenario/policy $E_{t}$ the aggregate residual demand faced by the dominant firms at hour $t$ is

$$
D_{t}^{r}(p)=\left(\frac{a_{t}}{b_{t}}-\frac{p}{b_{t}}+E_{t}\right)-\left(f_{t}+g_{t} p+I_{t}\right)
$$

where all parameters vary across the time. Each dominant firm takes its rivals' output fixed and maximizes its profit subject to the production constraints for each time. 
We exhibit the market outcomes and air pollution levels with respect to the export scenarios in Table 8. For the sake of briefness we only focus on the hours of March 2008, which is the last month in our study period. In the same table, to be conformable with the import analysis we stick to the same notation (via a minor abuse) as such $\mathrm{E}=0, \mathrm{E}=\mathrm{E}$, and $\mathrm{E}=2 \mathrm{E}$ mean the exports are zero, at the current levels, and twice the current levels, resp. We first compute the hourly equilibrium productions, market prices and demand quantities and then report the price and quantity distributions and the total welfare and emission levels in Table 8. As reported in the table, increase in exports lead to price increases as the total market demand increases. The price volatility goes up when exports double, and goes down when exports do not occur at all. Third and fourth moments of the price distribution are decreasing as the exports increase. The distribution of the market demand quantity has the similar features of first and second moments as with the price distribution, but the differences arise in the higher moments. Similar to the imports, the increase in export activities causes welfare improvements.

Table 8: Market outcomes and emissions in March 2008 with respect to change in export levels.

\begin{tabular}{|l|l|l|l|}
\hline Export level & $\mathrm{E}=0$ & $\mathrm{E}=\mathrm{E}$ & $\mathrm{E}=2 \mathrm{E}$ \\
\hline Price (\$) & & & \\
Average price & 51.62 & 58.65 & 65.99 \\
St. dev. & 20.74 & 22.95 & 25.47 \\
\hline Demand quantity (MWh) & & & \\
Average demand & 18,542 & 19,477 & 20,352 \\
St. dev & 1,593 & 1,628 & 1,663 \\
\hline & & & \\
\hline Total DWL (\$) & $30,212,212$ & $27,913,605$ & $19,466,709$ \\
\hline Change in Welfare (\$) & - & $2,298,607$ & $8,446,896$ \\
\hline & & & \\
\hline Total Emissions (ton) & & & \\
\hline NOx & 1,194 & 1,620 & 2,301 \\
\hline S02 & 1,745 & 3,136 & 4,959 \\
\hline CO2 & $1,307,416$ & $1,892,464$ & $2,442,874$ \\
\hline
\end{tabular}

Exporting twice the current levels results in higher $\mathrm{NOx}, \mathrm{SO} 2$, and $\mathrm{CO} 2$ emissions as the electricity production increases, but the significant rate of change is observed in the $\mathrm{SO} 2$ emissions, implying more coal-fired generation by the OPG. Indeed, this is clear in Table 9 where we depict the emissions released by the firms in the same period. 
Note that, similar to import scenarios, Brookfield emissions are constant over export scenarios as its small capacity gas-fired production is binding.

Table 9: Equilibrium total emission levels (in tons) in March 2008 over firms as exports vary.

\begin{tabular}{|llrrc|}
\hline & & OPG & BROOKFIELD & FRINGE \\
\hline $\mathbf{E}=\mathbf{0}$ & NOx & 550 & 28 & 616 \\
& SO2 & 1,745 & 0 & 0 \\
& CO2 & 653,038 & 25,674 & 628,704 \\
\hline $\mathbf{E}=\mathbf{E}$ & NOx & 888 & 28 & 704 \\
& SO2 & 3,136 & 0 & 0 \\
& CO2 & $1,162,208$ & 25,674 & 704,510 \\
\hline $\mathbf{E}=\mathbf{2 E}$ & NOx & 1,485 & 28 & 788 \\
& SO2 & 4,960 & 0 & 0 \\
& CO2 & $1,644,772$ & 25,674 & 772,429 \\
\hline
\end{tabular}

In all emission types the largest producer OPG is the most polluter. In particular, all firms pollute more as the export demand rises, but the significant polluters are the OPG, who is the sole source of $\mathrm{SO}$, and the fringe firms, who emits considerable amount of $\mathrm{CO} 2$, mainly stemming from their oil and gas-fired generators.

In comparing the effects of imports to the effects of exports, the average market prices are decreasing in import levels and increasing in export levels, and the rate of changes in prices are asymmetric. The average market prices in March are 63.55, 58.65, and 53.93 for $\mathrm{I}=0, \mathrm{I}=\mathrm{I}$, and $\mathrm{I}=2 \mathrm{I}$, resp. They are $51.62,58.65$, and 65.99 for $\mathrm{E}=0, \mathrm{E}=\mathrm{E}$, and $\mathrm{E}=2 \mathrm{E}$, resp. Note that $\mathrm{I}=\mathrm{I}$ and $\mathrm{E}=\mathrm{E}$ represent the same market setting in which hourly exports and imports are at the actual values, hence the market prices are the same. Given the actual exports, the change in import levels cause $7.7 \%$ price reduction from $\mathrm{I}=0$ to $\mathrm{I}=\mathrm{I}$, and $8.1 \%$ price reduction from $\mathrm{I}=\mathrm{I}$ to $\mathrm{I}=2 \mathrm{I}$. Given the actual imports, the change in export levels lead to $13.6 \%$ price increase from $E=0$ to $\mathrm{E}=\mathrm{E}$, and to $12.5 \%$ price hike from $\mathrm{E}=\mathrm{E}$ to $\mathrm{E}=2 \mathrm{E}$. The highest and lowest average prices are observed under the exports scenarios than the imports scenarios. We observe the same pattern in emissions when contrasting Tables 6 and 9. In the market the lowest and highest NOx levels are observed under the cases $\mathrm{E}=0$, and $\mathrm{E}=2 \mathrm{E}$. The same holds for $\mathrm{SO} 2$ and $\mathrm{CO} 2$ emissions as well. Mainly, the smallest level of total CO2 emissions in the imports scenarios, which is $1,514,742$ 
tons, is observed when imports double $(\mathrm{I}=2 \mathrm{I})$, however the lowest level is 1,307,416 tons when exports decrease to zero $(E=0)$ in March. The worst case scenario for $\mathrm{C} 02$ emissions happens to be $2,442,874$ tons when the export demand doubles $(E=2 E)$ from the current levels.

\section{Concluding Remarks}

The salience of electricity markets and their impact on the environment are withstanding. This paper studies new issues which are pertinent to the wholesale electricity markets. These are mainly examination of electricity trade and its impact on the air emissions and the total surplus. In an equilibrium model we have included Ontario's interregional trade (with Manitoba and Quebec) and international trade (with the neighboring states New York, Minnesota and Michigan) as its energy transfers are significant and there is a rich and unique data set available. We have modeled the Ontario wholesale market incorporating all of the active generators and their strategic reactions in a dominant firms and fringe suppliers market setting. We show that our competition model has a high predictive power and outstrips the IESO predictions. Given its predictive power we simulate the model with plausible scenarios incorporating no imports and high imports situations to measure trade implications on the welfare and air quality in Ontario. After constructing marginal cost curves and estimating market demand curve for each hour, we run the model to obtain the hourly production quantities of generators/firms, and then use the emission rates to calculate the amount of $\mathrm{NOx}, \mathrm{SO} 2$ and $\mathrm{CO} 2$ gasses released by each generator and firm. We find that when the hourly imports double from the current levels, the $\mathrm{CO} 2$ emissions decrease around $13 \%$, and the market prices reduce 5.4\%. If there would not be any trade between the Ontario market and the neighboring markets (NY, MN, MI, QC, and MB), the $\mathrm{CO} 2$, SO2, and NOx emissions would increase $12 \%, 22 \%, 16 \%$, resp., and the average market price would go up $5.8 \%$, and the price volatility would rise $12 \%$. The welfare gain from the trade is around $50 \%$ as a result of trade compared to autarky. Also, we measure the welfare loss when market prices are negative and find that the loss is very small - the DWL with negative prices is just $0.016 \%$ of the total welfare loss in the year.

Our findings have some implications on the recent Renewable Energy Laws implemented by many states and countries. In connection with the current phenomenon of green energy investments such as wind power generation, for example, Kaffine et al. (2013) find in an econometric estimation that emission savings from wind power in Texas (ERCOT) are $1.3 \mathrm{lbs}$ 
for $\mathrm{SO} 2,0.79 \mathrm{lbs}$ for $\mathrm{NOx}$, and 0.52 tons for $\mathrm{CO} 2$ per MWh wind generation. Our emission savings in Ontario due to trade have the similar impact as in Texas. Governments give large subsidies to the green energy producers including wind and solar generators. These subsidies are often suboptimal and inefficient, and distort the market outcomes as they are determined by regulatory agencies. However, we argue that trade activities could be used as an alternative mechanism and be fostered via transmission investments to abate air emissions. Furthermore, trade brings about efficiency because imports and exports are priced in the (wholesale) market.

Although our predictions for the market and firm levels are close to the realizations and are better than the system operator's predictions, we observe some differences at the generators level, which can naturally be expected. The main difference in production stems from the allocation of hydro resources, which ultimately affects the distribution of outputs from coal plants and other generation sources. This difference is not a surprising result as the actual productions are affected by the network constraints, interconnection capacities, generation specific constraints (ramp-up and ramp-down rates, start-up and shut down costs), dynamic considerations in power generation process (especially in hydropower reservoir management), and uncertainties in demand and supply sides, which have been ignored in the model. In the model we also made a number of simplifying assumptions such as smoothed cost curves and linear demand. All these factors can explain the minor differences between the actual and model outcomes.

Although we show how emissions vary with respect to change in import/export levels, a natural question arises with respect to the emission savings from trade: do we really expect emissions reduction in the region? The answer would be "yes". First, Ontario heavily imports from hydrobased Quebec and Manitoba markets. For example, during 2002-2008 Ontario's imports from Quebec have increased on average 18\% per year. Second, there is no cap and trade program in Ontario and power producers only need to purchase government issued permits to be able to produce from fossil-fuel-fired generators. The absence of this program can cause reductions in emissions. Third, it is not only Ontario that benefits from trade but also other big markets such as New York and Michigan who heavily import from the neighboring hydro-based Canadian markets to reduce their costs and abate the air pollution. Fourth, trade is also beneficial for Quebec and Manitoba markets such that during their off-peak periods they import low cost and 
clean base-load production (such as nuclear and wind) from Ontario, New York, and Michigan markets (each has more than $25 \%$ nuclear generation in their production portfolios) so as to sell their valuable hydro generation to these markets during peak times. Consequently, power trade could give rise to economical and environmentally friendly transactions in the region.

While exports are part of total market demand, we were able to separate the exports from the market demand and measure the impact of certain export scenarios on market outcomes and air quality. We find that relative to the import scenarios, the extreme market outcomes and emissions are pronounced under the export scenarios.

One could do a robustness check of the results by ignoring emission permit prices. However, we speculate that the results would not change as the fuel costs are salient and the permit prices are low and contribute only too little (less than $4 \%$ ) to the total marginal cost of production.

\section{REFERENCES}

Amor, M.B, P.O. Pineau, C. Gaudreault, and J. Samson, "Electricity Trade and GHG emissions:

Assessment of Quebec's hydropower in the Northeastern American market (2006-2008)", Energy Policy, 39:1711-1721, 2011.

Antweiler, W., B. Copeland, and S. Taylor, "Is Free Trade Good for the Environment?", AER, 91 (4): 877-908, 2001.

Borenstein, S., and J. Bushnell, “An Empirical Analysis of the Potential for Market Power in California's Electricity Industry”, Journal of Industrial Economics, XLVII (3), 1999.

Borenstein, S., J. Bushnell, and S. Stoft, "The Competitive Effects of Transmission Capacity in a Deregulated Electricity Industry," Rand Journal of Economics, 31(2): 294-325, 2000.

Borenstein, S., J. Bushnell, and F. Wolak, "Measuring Market Inefficiencies in California's Restructured Wholesale Electricity Market", AER, vol. 92, December 2002.

Cole, M. A., "Trade, the pollution haven hypothesis and the environmental Kuznets curve: examining the linkages.” Ecological Economics, 48 (1): 71 - 81, 2004.

Elkhafif, M.A.T. "Estimating disaggregated price elasticities in industrial energy demand". Energy Journal, 13 (4), 1992.

Fowlie, M, S. Holland, and E. Mansur, "What Do Emissions Markets Deliver and to Whom? Evidence

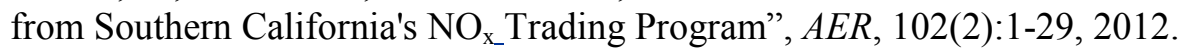

Frankel, J. A., and A. K. Rose, "Is Trade Good or Bad for the Environment? Sorting out the Causality." Review of Economics and Statistics, 87 (1): 85-91, 2005. 
Genc, T., "Discriminatory versus Uniform-price Electricity Auctions with Supply Function Equilibrium", Journal of Optimization Theory and Applications, 140(1): 9-31, 2009.

Genc, T., and S. Reynolds, "Supply Function Equilibria with Capacity Constraints and Pivotal Suppliers", International Journal of Industrial Organization, 29(4): 432-442, 2011.

Genc, T.S., P. Pineau, and E. Yazgan, "Electricity Trade Patterns in a Network", working paper, University of Guelph, 2013.

Green, R. and D. Newbery, "Competition in the British Electricity Spot Market", Journal of Political Economy, v. 100, no. 51992.

Grether, J.M., and J. De Melo, "Challenges to Globalization: Analyzing the Economics", Chicago: University Of Chicago Press chapter Globalization and dirty industries: Do pollution havens matter?, 2004.

Hortacsu, A. and S. Puller, "Understanding Strategic Models of Bidding in Deregulated Electricity Markets: A Case Study of ERCOT”, RAND Journal of Economics 39(1): 86-114, Spring 2008.

IESO, Ontario Transmission System, IESO_REP_0265v15.0, Toronto: IESO, Aug. 21, 2009a.

Joskow, P., and E. Kahn, "A Quantitative Analysis of Pricing Behavior in California's Wholesale Electricity Market During 2000”, Energy Journal, vol. 23, pp. 1-35, 2002.

Kaffine, D., B. McBee, and J. Lieskovsky, "Emissions Savings from Wind Power Generation in Texas", Energy Journal, 34(1): 155-175, 2013.

Levinson, A., " Technology, International Trade, and Pollution from US Manufacturing, AER, 99:5, 2177-2192, 2009.

Lijesen, M., “The real-time price elasticity of electricity”, Energy Economics, 29:249-258, 2007.

Mansur, E. "Measuring Welfare in Restructured Electricity Markets" Review of Economics and Statistics, 90:2, 369-386, 2008.

Peters, G. P., J. C. Minx, C. L. Weber, and O. Edenhofer, "Growth in emission transfers via international trade form 1990 to 2008." Proceedings of the National Academy of Sciences, 108 (21): 8903-8908, 2011.

Wolak, F.A., "Quantifying the Supply-Side Benefits from Forward Contracting in Wholesale Electricity Markets," Journal of Applied Econometrics, 22:1179-1209, 2007.

Wolak, F.A, "Measuring the Competitiveness Benefits of a Transmission Investment Policy: The Case of the Alberta Electricity Market", mimeo, Stanford University, 2012.

Wolfram, C.D. "Measuring Duopoly Power in the British Electricity Spot Market”, AER, vol.89, 1999. 


\section{For Online Publication}

\section{APPENDIX A}

\section{DATA}

In the calibrations of the model a detailed plant and market level data provided by the IESO, the Environment Canada, and the Statistics Canada have been used. The plant level data are comprised of the hourly outputs and available capacities of the generators (there are 563 registered generators in the Ontario wholesale electricity market), technical characteristics of all generators including heat rate, age, NOx and $\mathrm{SO} 2$ emission rates, energy content of each type of fuel used (coal, nuclear, gas, oil, biomass, etc), and the amount of fuel used from each fuel type, and the financial data such as the dollar amount spent for each type of fuel and permit prices for the air pollutants $\mathrm{NOx}$ and $\mathrm{SO} 2$. We have also used hourly market price and demand quantity, and hour-ahead hourly price predictions called pre-dispatch prices (i.e., the hourly market price estimations) of the IESO. The data sets we have obtained cover the time frame of Jan 1, 2004Dec 31, 2009, and we used one year of the hourly data accounting for 8784 observations for each variable, (starting from April 1, 2007, the time that the IESO started to publish the pre-dispatch data and ending with March 31, 2008). The data obtained from the IESO, Statistics Canada and Environment Canada was in a raw format (xml files), which were converted into a workable database.

\section{Marginal Production Costs}

There are 563 registered generators in the Ontario market (source: Environment Canada: Canadian Module Unit List-The Canadian Module Unit List is a fundamental modeling input to the Canadian IPM Base Case 2004. It is an inventory of all currently operating (or existing) electric generating units (EGUs) and planned-committed units and their relevant characteristics. http://www.ec.gc.ca/air/default.asp?lang=En\&n=D6C16D01-1)

Fuel consumed, dollar amount spent, energy content change every year and the data is provided by Statistics Canada (source: Statistics Canada (2009) Electric Power Generation, Transmission and Distribution - 2007, Catalogue no. 57-202-X) 
We calculate the emission costs as follows. Given the NOx and SO2 rates $(\mathrm{g} / \mathrm{MJ})$ and the heat rate $(\mathrm{kj} / \mathrm{kwh})$ for each generator, we multiply the emission rate with the heat rate and the appropriate conversion rate to find the quantity of emission released (pound) per electricity production (MWh).

The $\mathrm{CO} 2$ emission rates of generators in Ontario have not been reported. Their rates could be calibrated using the heat rates and fuels' $\mathrm{CO} 2$ contents. Unfortunately, we do not have the data for $\mathrm{CO} 2$ fuel contents, which greatly vary even among the given fuel type. For example, coal has several subcategories with different $\mathrm{CO} 2$ contents depending on whether it is anthracite, lignite, sub-bituminous or bituminous. Due to these reasons, we will employ an alternative approach which is directly using U.S. plant data to approximate the $\mathrm{CO} 2$ emission rates in Ontario. This could be a reasonable approximation as they both use the generators made by the same companies such a General Electric, Honeywell, Siemens, etc. In particular, we approximate $\mathrm{CO} 2$ rates of natural gas, coal (bituminous, sub-bituminous, and lignite), diesel fuel oil, and wood and wood waste fired generators. Specifically, we look at the EPA 2007 eGrid report on generation plants in the U.S. They report various kinds of emissions for all U.S. generation plants; a plant may have multiple generation units. The eGrid report aggregates information to the plant level. We take data for the most common types of fossil fuel plants and take the average $\mathrm{CO} 2$ emissions rate for each of these plant types. The reported data has some obvious errors; negative emissions, and some extremely high emission numbers. After removing obvious outliers, we are left with 2,435 fossil fuel plants. We use the average $\mathrm{CO} 2$ emissions (in pounds of $\mathrm{CO} 2$ per $\mathrm{MWh}$ ) of those plants. In particular we use the following emission rates per production technology: Natural Gas 1265.26 (in lb/MWh); Bituminous - Coal 2079.66; Diesel Fuel Oil 1855.50; Lignite - Coal 2491.05; Sub-bituminous - Coal 2259.61; Wood waste (WDL and WDS categories in eGrid) 368.27. Then we assign those $\mathrm{CO} 2$ emissions to the Ontario generators with regard to their production technologies.

NOx releasing production technologies use diesel, refinery gas, wood and wood waste, landfill gas, coal (lignite, bituminous, sub-bituminous), natural gas, and oil. Among these technologies, only coal plants generate $\mathrm{SO} 2$ emission. 


\section{Calculating marginal fuel cost of a generator}

Given the type and amount of the fuel each generator uses, each generator's heat rate, energy content of each fuel type, and the dollar amount spent on each fuel type, we calculate the marginal fuel cost of a generator as follows:

MC_fuel_gen=Heat rate (in $\mathrm{kj} / \mathrm{kwh}) * \$($ dollar spent on fuel)/[total fuel consumption (in ton)*Energy content (in kj/kg)] $=\$ / \mathrm{MWh}$

Technically this formulation assumes that the average variable fuel cost equals the marginal fuel cost.

\section{Calculating marginal emission cost of a generator}

Emission permits are traded for NOx and $\mathrm{SO} 2$ gasses. The emission costs are calculated as follows.

$\mathrm{SO} 2$ emission cost for a generator is $=$ Heat rate of generator* $\mathrm{SO} 2$ rate of generator* price of $\mathrm{SO} 2$ emission permit

NOx emission cost for a generator is $=$ Heat rate of generator* NOx rate of generator*price of NOx emission permit.

\section{$\underline{\text { Total marginal cost of production for a generator }}$}

Total marginal cost for a generator is the summation of MC_fuel_gen, SO2 emission cost for the generator, and NOx emission cost for the generator.

Since we have used the aggregated marginal costs of OPG and the fringe firms, due to the large number of generators they own, our model computes the aggregated equilibrium outputs of these firms (because OPG and fringe in total have more than hundred generators the model does not compute equilibrium output from each generator, instead reports total production from these producers). However, the model computes the outputs of generators of the Bruce and Brookfield, as they have a few generation units relative to OPG and the fringe firms. As we have the aggregate production cost function for OPG and fringe, we allocate the total output of these producers in merit order, i.e., with respect to their costs (assuming that firms generate electricity in merit order, starting with low cost technologies and then using costly technologies). This 
allocation is consistent with the profit maximization behavior, as these firms maximize profits they also minimize their costs. Since Brookfield has low cost (wind and hydro) and high cost (natural gas-fired) technologies, its cost function is a step-cost function; hence we are able to calculate outputs from low cost and high cost generators. However, this was not feasible with OPG and fringe producers, as the computational complexity would increase.

For each hour we construct a different marginal cost function since the available capacities of at least one generator of a firm will change. After obtaining a marginal cost function we fit into a continuous function selected by highest R-square. We approximate the step marginal cost function by a smooth curve because of the high number of steps (over 60 steps, which highly complicates the optimization). For example, on April 1, 2007, hour 9, we obtain a quadratic marginal cost function for OPG. The marginal cost at zero output is zero because OPG has hydro generators which operate at zero marginal cost (of fuel). Note that for the same day marginal cost function coefficients may change due to hourly changing available capacities of over sixty generators of OPG. For instance, on the same day next hour, April 1, hour 10, we have a different cost function, a quadratic marginal cost function that has different cost coefficients than the ones at hour 9 (see figures A1 and A2).

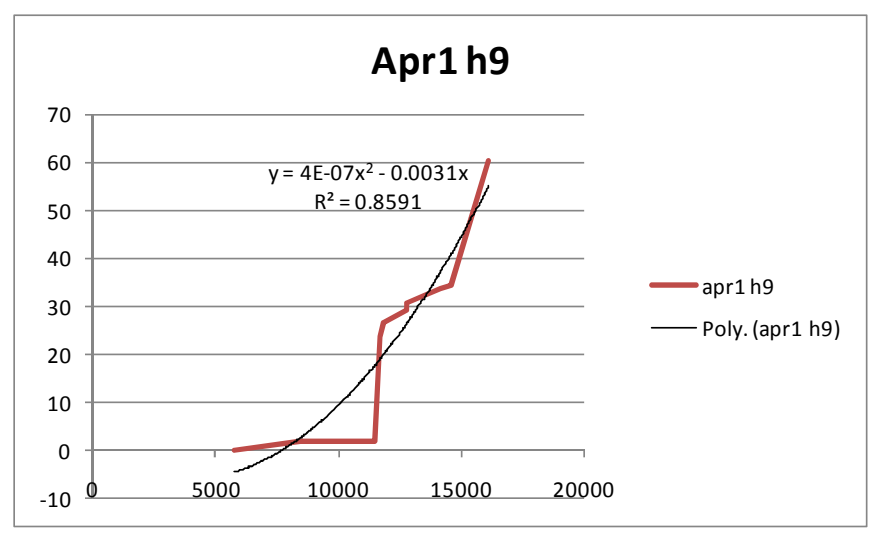

Figure A1: OPG marginal production function on April 1 ${ }^{\text {st }}$, hour 9, 2007. 


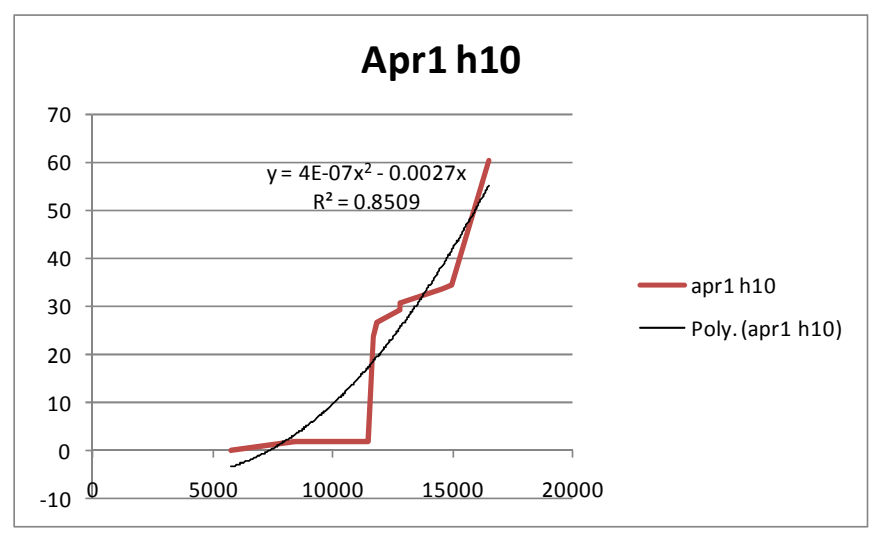

Figure A2: OPG marginal production function on April $1^{\text {st }}$, hour 10, 2007.

Given the available capacities and marginal costs for each hour we construct and smooth fringe suppliers' marginal production cost functions. In Figure A3, we draw the inverse marginal cost curve as a function of available capacity in April 1 hour 1. The best fitting smooth function is the fourth degree polynomial for the marginal cost curve. We draw the marginal cost function in Figure A4 with linear and fourth degree approximations. In terms of goodness of fit, there is little difference between a linear function and the fourth degree polynomial function. We observe similar patterns in other hours in the year. Also, for the sake of tractability and avoiding the multiple equilibrium issue with the forth degree polynomial, we assume linear supply curve for each hour for the fringe suppliers.

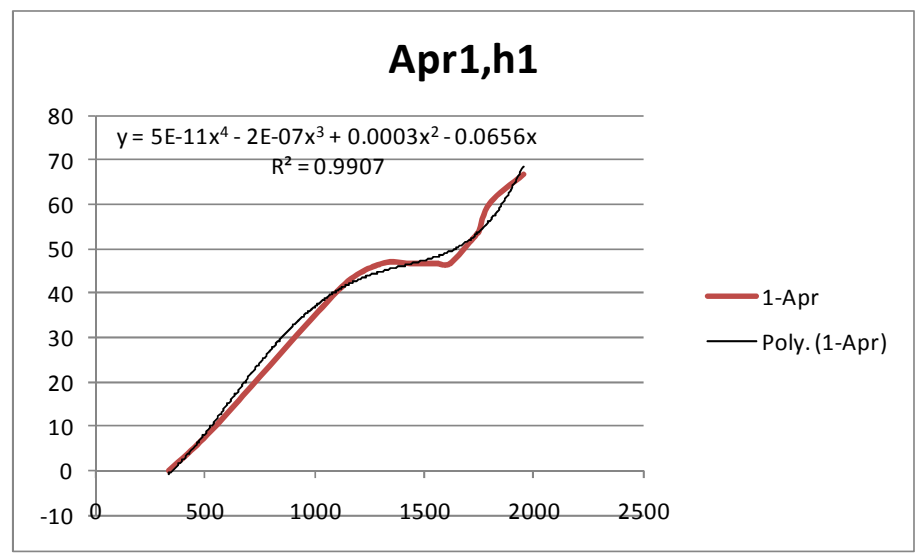

Figure A3: Inverse Fringe supply curve and the approximation. 


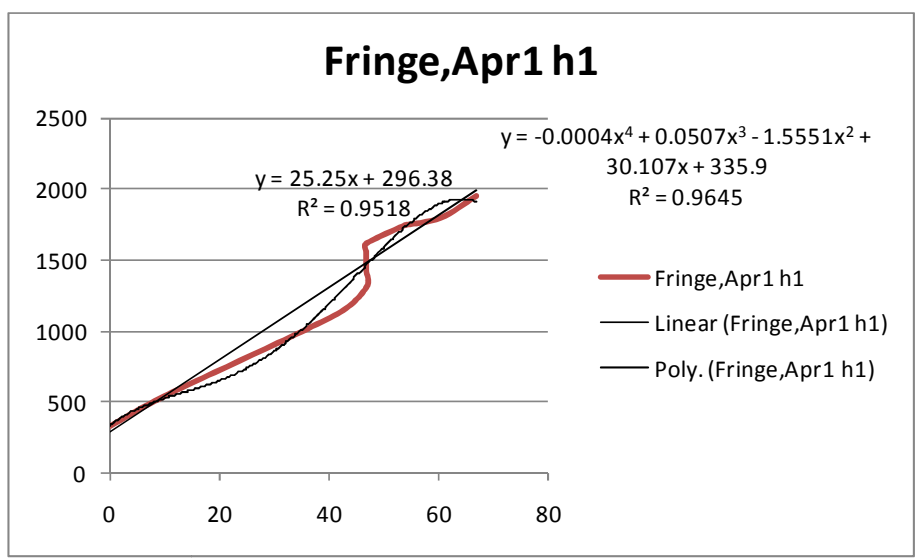

Figure A4: Fringe supply curve, S(p), and approximations with a linear curve and fourth degree polynomial curve.

The marginal cost curves for the Bruce Nuclear and the Brookfield Energy will be step cost functions. The Brookfield has two types of production technologies, renewables (hydro and wind) and the fossil-fuel fired (natural gas) generators with the same characteristics. The Bruce has several nuclear plants with the same technological characteristics and hence will have a onestep cost in its marginal cost function. We draw their marginal cost curves below.

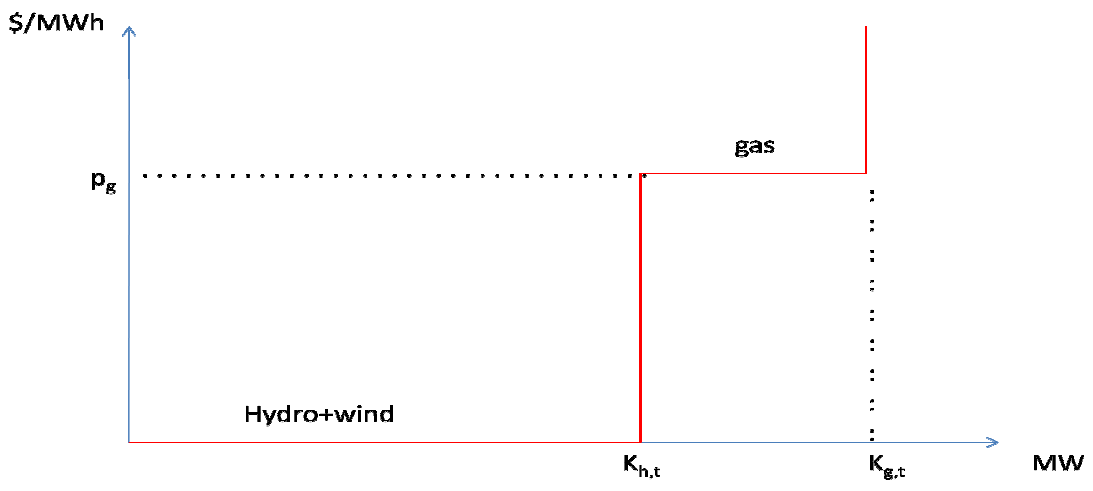

Figure A5: Brookfield Renewable Energy Inc's marginal cost function. 


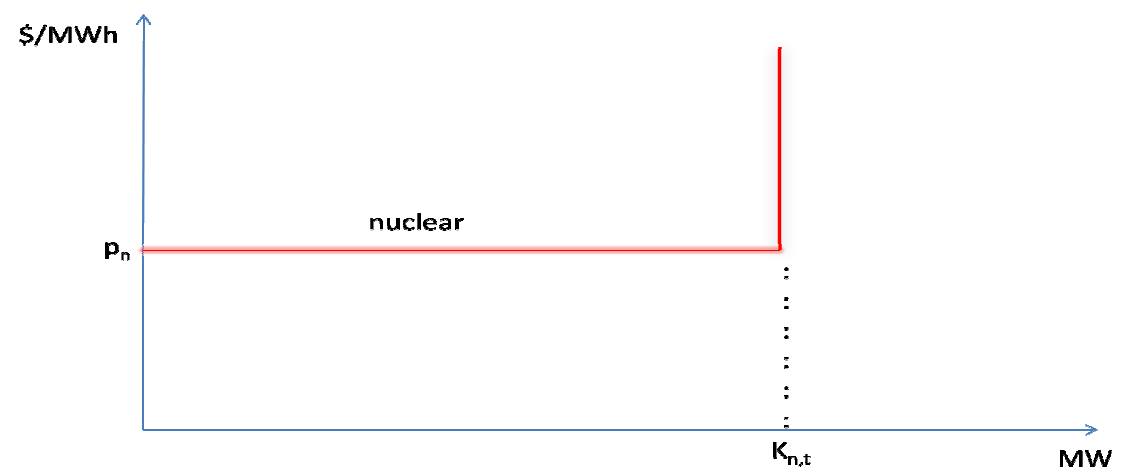

Figure A6: Bruce Nuclear Inc's marginal cost function.

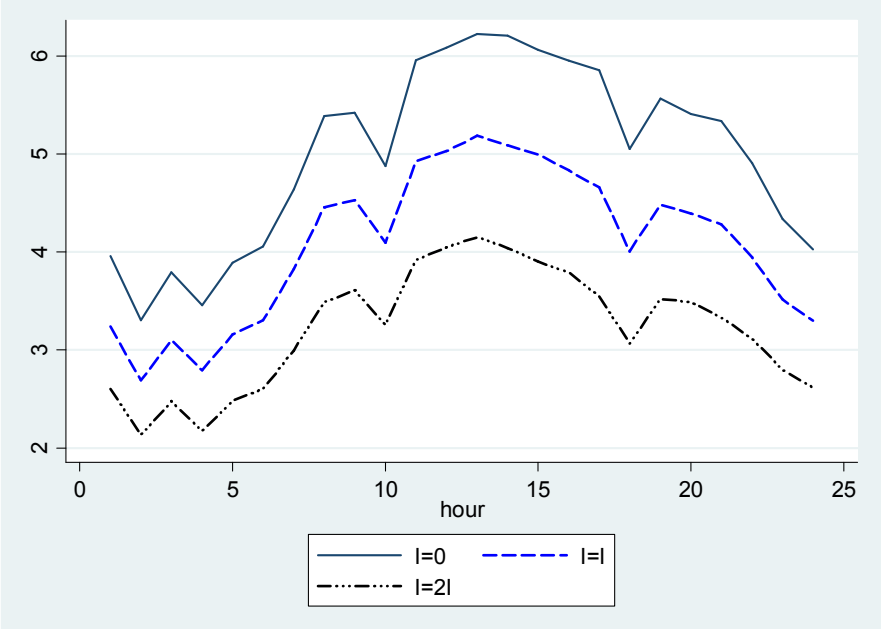

Figure A7: Average hourly SO2 emissions in ton (y-axis) by the hour of the day (x axis). 


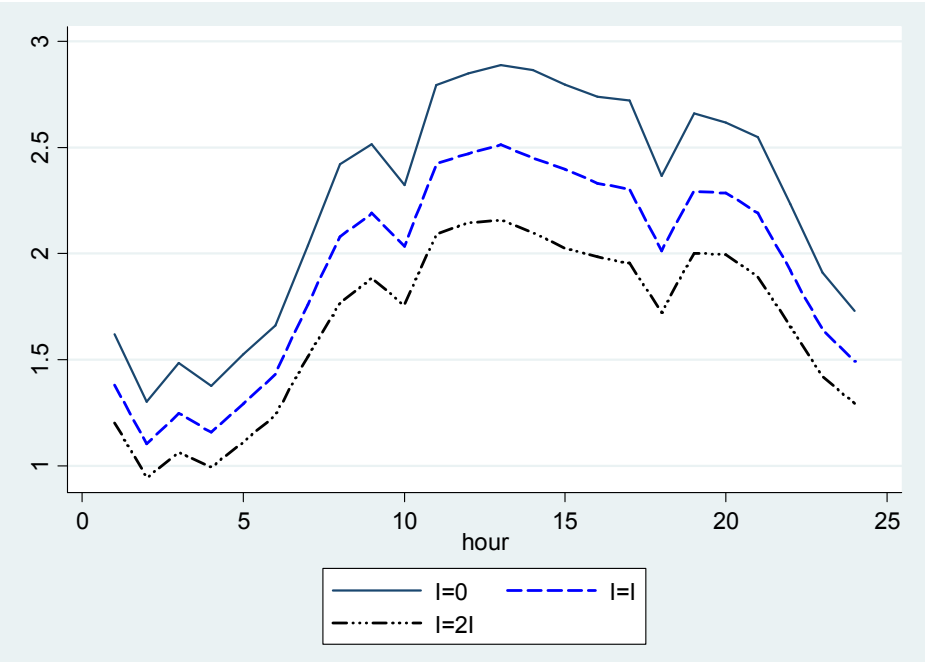

Figure A8: Average hourly NOx emissions in ton (y-axis) by the hour of the day (x axis).

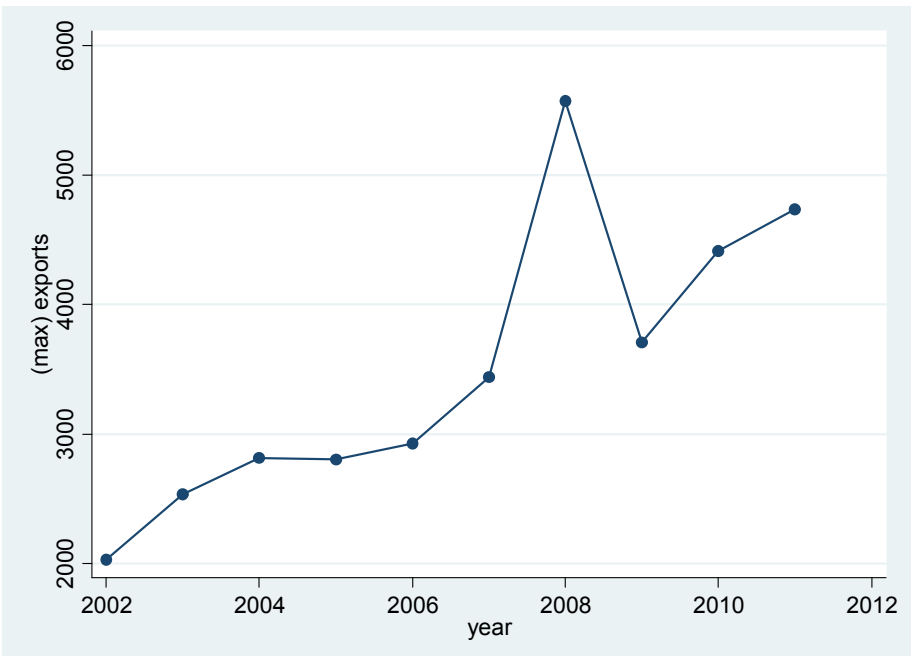

Figure A9 - Maximum hourly export levels in Ontario 


\section{APPENDIX B}

We report the average monthly MAE calculations for the model and IESO predictions below. Note that the average MAE over the months is slightly different than the average MAE over the all hours reported in Table 1 due to the different number of hours in each month.

\begin{tabular}{|c|c|c|}
\hline \multirow[b]{2}{*}{ Period } & \multicolumn{2}{|l|}{$\underline{\text { MAE }}$} \\
\hline & $\underline{\text { Estimation }}$ & $\underline{\text { IESO }}$ \\
\hline April & 4.200022069 & $\overline{13.41502778}$ \\
\hline May & 2.358839126 & 11.54591398 \\
\hline June & 3.588778722 & 12.05448611 \\
\hline July & 3.552405524 & 9.741572581 \\
\hline August & 4.069345753 & 10.22072581 \\
\hline September & 2.947445894 & 9.114555556 \\
\hline October & 2.851316989 & 10.64819892 \\
\hline November & 2.782174625 & 10.51980556 \\
\hline December & 2.85719668 & 10.7708871 \\
\hline January & 3.325186855 & 11.27635753 \\
\hline February & 4.512862874 & 15.06418103 \\
\hline March & 2.487704435 & 14.99854839 \\
\hline $\begin{array}{l}\text { Averaged } \\
\text { over }\end{array}$ & & \\
\hline months & 3.294439962 & 11.6141883 \\
\hline
\end{tabular}

